\title{
A Nanodrug Coated with Membrane from Brain Microvascular Endothelial Cells Protects against Experimental Cerebral Malaria
}

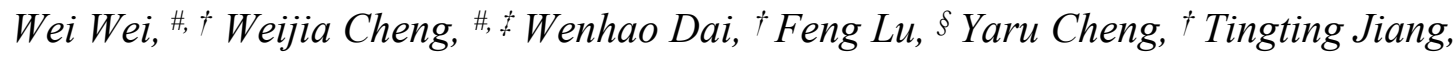

${ }^{\star}$ Zhenyu Ren, ${ }^{\S}$ Yiting Xie, ${ }^{\star}$ Jiahui Xu, ${ }^{\S}$ Qun Zhao, ${ }^{\star}$ Xianjun Yu, ${ }^{\star}$ Yi Yin, ${ }^{\S}$ Jian Li, *,

\# Haifeng Dong *,,+

$\dagger$ Beijing Key Laboratory for Bioengineering and Sensing Technology, School of Chemistry and Bioengineering, University of Science and Technology Beijing, Beijing 100083, China.

* Department of Human Parasitology, School of Basic Medical Sciences, Hubei University of Medicine, Shiyan 442000, China.

" Marshall Laboratory of Biomedical Engineering, Research Center for Biosensor and Nanotheranostic, School of Biomedical Engineering, Health Science Center, Shenzhen University, Shenzhen 518060, China.

$\S$ School of Medicine, Yangzhou University, Yangzhou 225009, China

\# These authors contributed equally.

*Corresponding Authors:

Jian Li, E-mail: yxlijian@163.com;

Haifeng Dong, E-mail: hfdong@ustb.edu.cn or hfdong@szu.edu.cn 


\section{Content}

EXPERIMENTAL SECTION

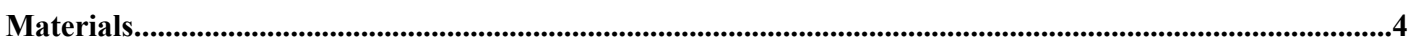

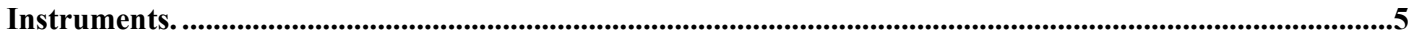

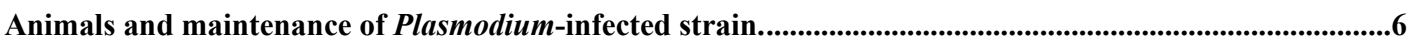

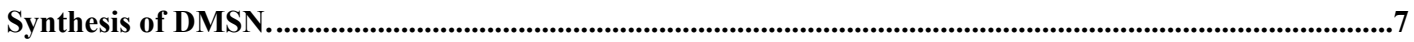

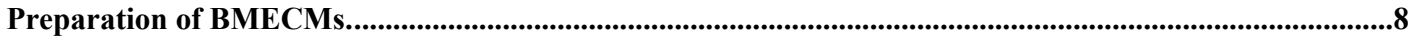

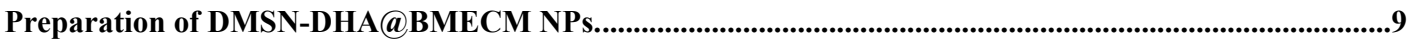

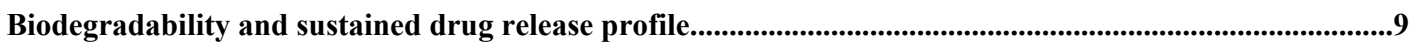

In vitro hemolysis analysis. ..............................................................................................................................11

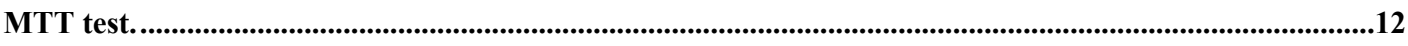

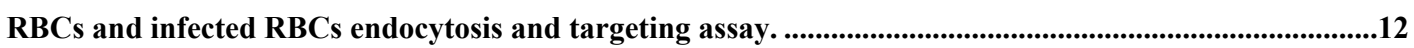

The self-target ability of DMSN@BMECM to the source brain microvascular endothelial cells.................14

Assessment of BBB permeability. ............................................................................................................................14

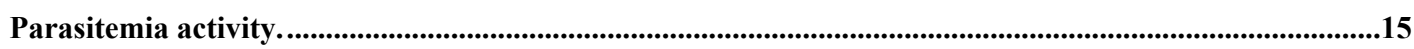

Histological analysis and deposited hemozoin analysis.............................................................................................15

Transcriptome sequencing and analysis.......................................................................................................16

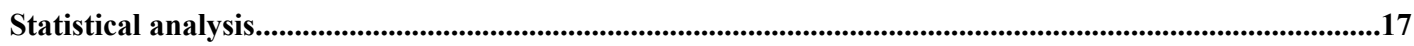

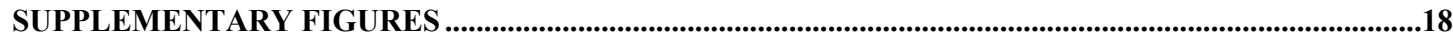

Figure S1. TEM characterization of magnified (a) dendritic DMSN, (b) pure bEnd.3 cell membrane, and (c) cell membrane coated DMSN; that was, DMSN@BMECM.

Figure S2. A nitrogen absorption-desorption isotherm and the corresponding pore-size distribution of DMSN.

Figure S3. Original images of data from SDS-PAGE and western blot experiments...................................19

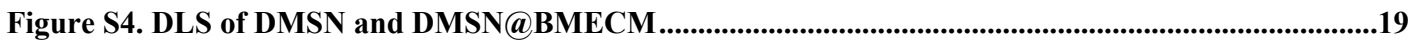

Figure S5. Zeta potential measurement analyses of DMSN and DMSN@BMECM. ...................................20

Figure S6. Stability analysis of DMSN-DHA@BMECM in PBS buffer for 7 days. .......................................20

Figure S7. TEM degradation images of DMSNs (200 $\mu \mathrm{g} / \mathrm{mL})$ in PBS (top), serum (middle) and $10 \mathrm{mM}$

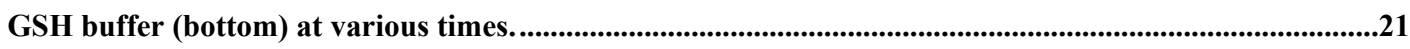

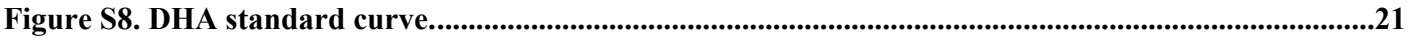

Figure S9. Representative images of HPLC analysis of DHA standards......................................................22

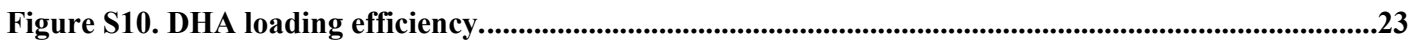


Figure S11. In vitro cytotoxicity of DMSN and DMSN@BMECM.

Figure S12. The binding ability of mice BMECM covered Nano-vector (DMSN@mBMECM) towards mice iRBCs induced by $P$. berghei ANKA $(P b A)$ in $C 57 B L / 6 N$ Mice model..

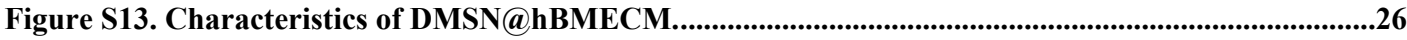

Figure S14. Positive control (HE and TO) for the flow cytometer test. .............................................................27

Figure S15. Typical CLSM images of bEnd.3 cells incubated with FITC-loaded DMSN@mBMECM or DMSN for $4 \mathrm{~h}$

Figure S16. CLSM images of fluorescent DMSN@mBMECM incubated with bEnd.3 cells (top) and 3T3 cells (bottom) for $4 \mathrm{~h}$.

Figure S17. FCM E1 region collected by PBS treated human brain microvascular endothelial cells.........30

Figure S18. SDS-PAGE electrophoresis and western blot analysis of the different human cell membranes 31

Figure S19. Flow charts of animal experiments .32

Figure S20. Fluorescence immunoassay experiment of mice brain tissues for different treatment groups. .33

Figure S21. FCM test of mice brain for different treatment groups. .34

Figure S22. Histological observations in brain tissue from $P b A$-infected $C 57 B L / 6 N$ mice. .35

Figure S23. Prussian blue-stained histological observation of liver and spleen from $P b A$-infected $C 57 B L / 6 N$ mice following various drug treatments. .36

Figure S24. Representative H\&E stained images of the spleen after different treatments...........................36

Figure S25. Original pictures and data for the RePu areas for the four treatment groups...........................37

Figure S26. Representative pictures for the number of RBCs in images of HE-stained spleen from $P b A$-infected $C 57 B L / 6 N$ mice after different treatments. . .38

Figure S27. Parasitaemia detection in blood from $\mathrm{PbA}$-infected $\mathrm{C57BL} / 6 \mathrm{~N}$ mice after drug treatment....39

Figure S28. Heatmap analysis of differentiated expressed genes (DEGs) . .40

Figure S29. mRNA enrichment images of data obtained from DHA- and DMSN-DHA-treated groups...41

Figure S30. mRNA enrichment images of data obtained from DHA- and

DMSN-DHA@BMECM-treated groups. . .42

Figure S31. mRNA enrichment images of data obtained from untreated and DHA-treated groups...........43

SUPPLEMENTARY TABLES

Table S1. The FCM data of hBMECs incubated with different human cell membrane clocked DMSN nano vectors.

Table S2. The RePu areas for the four treatment groups. 


\section{EXPERIMENTAL SECTION}

\section{Materials.}

Dihydroartemisinin (DHA, purity $\geq 99 \%$ ) and bis[3-(triethoxysilyl)propyl] tetrasulfide were purchased from Aladdin Co., Ltd (Shanghai, China). HPLC-grade acetonitrile and DMSO were purchased from Macklin Inc. (Shanghai, China). Tetraethyl orthosilicate (TEOS), N-cetyltrimethylammonium bromide (CTAB), triethanolamine (TEA), Evans blue solution, sodium salicylate (NaSaI), phenylmethane sulfonyl fluoride, and 3-(4,5-dimethyl-2-thiazolyl)-2,5-diphenyl-2-H-tetrazolium bromide (MTT) reagent were obtained from Sigma-Aldrich (Shanghai, China). Hoechst 33342, propidium iodide (PI), and calcein-AM were obtained from Yeasen Biotech. Co., Ltd. (Shanghai, China). Dihydroartemisinin (DHA) standard, phosphate buffer saline (PBS, pH 7.4), Dulbecco's Modified Eagle's Medium (DMEM), Alsever's solution, penicillin-streptomycin, and trypsin-EDTA were purchased from Solarbio Science \& Technology Co., Ltd. (Beijing, China). TRIzol reagent was purchased from Invitrogen (CA, United States). NEBNext Ultra RNA library prep kit for Illumina was purchased from New England Biolabs, Inc (Ipswich, MA, USA). Fetal bovine serum (FBS) and Opti-MEM medium were purchased from Gibco Life Technologies (Grand Island, NY, USA). Continuous carbon/formvar support film was brought from Zhongjingkeyi (Beijing) Film Technology Co., Ltd. (Beijing, China). The primary antibodies ICAM-1 rabbit monoclonal antibody, VCAM-1 rabbit monoclonal antibody, CD31 rabbit monoclonal antibody, Actin mouse monoclonal antibody, and 
GAPDH rabbit monoclonal antibody were purchased from Beyotime Biotech Co., Ltd. (Shanghai, China). The goat-anti-rabbit IgG/HRP secondary antibody and goat-anti-mouse IgG/HRP secondary antibody were purchased from Solarbio Science \& Technology Co., Ltd. (Beijing, China). The bicinchoninic acid (BCA) protein assay kit and membrane protein extraction kit were purchased from Beyotime Biotech Co., Ltd. (Shanghai, China). Unless otherwise stated, all reagents were analytically pure and used as received without purification. The cells used in our systems were listed as follows: mouse brain microvascular endothelial cells (bEnd.3 cells) and human brain microvascular endothelial cells (primary isolation) were provided by Procell Life Science\&Technology Co., Ltd. (Wuhan, China). Normal human dermal fibroblast cell (NHDF), human malignant glioblastoma cell (U87MG), human umbilical vein endothelial cell (HUVEC) were purchased from Cell Resource Center, Institute of Basic Medical Sciences, Chinese Academy of Medical Sciences (Beijing, China). Human normal RBC came from healthy volunteers.

\section{Instruments.}

DHA mass analysis was carried out using an EC2006 high-performance liquid chromatographic (HPLC) apparatus supplied by Yilite Analytical Instrument Co., Ltd. (Dalian, China). The morphologies of DMSN and DMSN@BMECM were observed with a transmission electron microscope (TEM, HT7700, Hitachi, Japan). Zeta potential analysis and dynamic light scattering (DLS) were obtained using a Zetasizer Nanosystem (ZS90, Malvern, UK). Nitrogen absorption-desorption isotherm and porosity assays were performed using a surface-area analyzer 
(QuadraSorb SI 2000-08, Quantachrome Instruments, USA). All fluorescence photographs were obtained on a CLSM (LSM710META, Zeiss, Germany). The hematoxylin and eosin (H\&E) slides were observed with an inverted fluorescent microscope (IX73, Olympus, Japan). Flow cytometry (NovoCyte, Agilent, USA) was used to analyze the endocytosis and targeting ability of the NPs, and all data were analyzed by NovoExpress software. RNA integrity was checked using an RNA Nano 6000 assay kit accompanying the Bioanalyzer 2100 system (Agilent Technologies, CA, USA). RNA purity and concentration were assessed using a NanoPhotometer spectrophotometer (IMPLEN, CA, USA) and a Qubit RNA assay kit using a Qubit 2.0 fluorometer (Life Technologies, CA, USA), respectively.

Animals and maintenance of Plasmodium-infected strain.

Female $C 57 B L / 6 N$ mice (15-18 g, 6-8 weeks old) were purchased from the HNSJA Co., Ltd. (Changsha, China) and maintained at the Animal Care Facilities of the Hubei University of Medicine. Mice were offered hygienic drinking water and fed a standard ad libitum mouse diet in protective cages. The female $C 57 B L / 6 \mathrm{~N}$ mice were used in four independent experiments: 24 for the survival studies, six for hemolysis analysis, eight for blood-brain barrier (BBB) analysis, eight for organ sampling, and histological analysis. Mice were adapted to their new environment for three days before experimentation. All mice were maintained in a $12 \mathrm{~h}$ light/dark cycle facility at room temperature and $60 \%$ relative humidity during the experiments. All efforts were made to minimize animal suffering. ${ }^{1}$ All animal experiments followed protocols approved by the Hubei University of Medicine. 
The P. berghei ANKA $(P b A)$ strain was maintained by successive infection of $C 57 B L / 6 N$ mice. Cryopreserved $P b A$ parasites were thawed and passaged once through $C 57 B L / 6 \mathrm{~N}$ mice before infecting experimental animals. Infections were initiated in $C 57 B L / 6 \mathrm{~N}$ mice via intraperitoneal (i.p.) injection of $1 \times 10^{6} \mathrm{PbA}$ parasitized RBCs. Mice were monitored daily for neurologic signs of cerebral malaria, such as coma, ataxia, and paralysis. ${ }^{2}$ The survival rate was recorded daily. Parasitemia was assessed by Giemsa-stained thin smears from mouse tail blood. The Ethical Review Committee of the Hubei University of Medicine approved the study, and laboratory animals' care was under institutional guidelines.

P. falciparum strain was maintained by infection of healthy human blood. The Ethical Review Committee of Yangzhou University approved the study, and all the experiment was under institutional guidelines.

\section{Synthesis of DMSN.}

The DMSN was synthesized according to our previous method with some modification $^{3}$. Using tetraethyl orthosilicate (TEOS) as the silicon source, triethanolamine (TEA) as the catalyst, and $\mathrm{CTAB} / \mathrm{NaSaI}$ as the structural guide agent, DMSN was prepared by introducing a tetrasulfide bond into the dendritic mesoporous skeleton through crosslinked bis[3-(triethoxysilyl)propyl] tetrasulfide. Briefly, $0.068 \mathrm{~g}$ TEA was dissolved in $25 \mathrm{~mL}$ of deionized water in a $50 \mathrm{~mL}$ round-bottomed flask and stirred in an oil bath at $80{ }^{\circ} \mathrm{C}$ for $0.5 \mathrm{~h} .380 \mathrm{mg}$ CTAB and $168 \mathrm{mg}$ sodium salicylate (NaSaI) were added and continuously stirred for another 1

h. Subsequently, a mixture of $2 \mathrm{~mL}$ of TEOS and $1.6 \mathrm{~mL}$ of 
bis(r-triethoxysilylpropyl) tetrasulfide were added to the above solution and stirred at $300 \mathrm{r} / \mathrm{min}$ for $12 \mathrm{~h}$. Finally, the template was washed away with multiple ethanol washes for three days. The DMSN NPs were collected by centrifuging at $8,000 \mathrm{r} / \mathrm{min}$ for $10 \mathrm{~min}$ and washed twice with deionized water. The resulting NPs were dried and weighed for further use. Fluorescent DMSN NPs and DMSN@BMECM NPs for confocal fluorescence microscopy and flow cytometry testing were prepared according to Shao's method ${ }^{4}$, which were tagged with FITC, Cy5, or Dil dyes.

\section{Preparation of BMECMs.}

The widely used immortalized mouse brain endothelial cell line bEnd.3 cell was chosen as the model. Brain cerebral microvascular endothelial cell membrane was obtained according to our previous work ${ }^{5}$ bEnd. 3 cells $\left(5 \times 10^{6}\right)$ were prepared in 10 $\mathrm{cm}$ cell culture dishes containing $8 \mathrm{~mL}$ Dulbecco's Modified Eagle's Medium (DMEM) supplemented with $1 \%$ penicillin-streptomycin and $10 \%(\mathrm{v} / \mathrm{v})$ fetal bovine serum (FBS) at $37^{\circ} \mathrm{C}$ in a humidified atmosphere containing $5 \% \mathrm{CO}$. Cell scrapers were used to detach cells after $72 \mathrm{~h}$ incubation, and the cells were collected by centrifugation at 2,000 r/min for $5 \mathrm{~min}$. All the collected cells were washed twice in PBS buffer $(10 \mathrm{mM}, \mathrm{pH}=7.4)$ and then suspended in membrane protein extraction Reagent A containing $1 \mathrm{mM}$ PMSF at $4{ }^{\circ} \mathrm{C}$ according to the instructions of the membrane protein extraction kit. The mixture was incubated for $15 \mathrm{~min}$ in an ice bath then centrifuged at 3,000 r/min for another $10 \mathrm{~min}$ at $4{ }^{\circ} \mathrm{C}$. After carefully collecting the liquid supernatant, the supernatant was centrifuged at $13,000 \mathrm{r} / \mathrm{min}$ for $30 \mathrm{~min}$ to obtain the membrane. The membrane was lyophilized and stored at $-80{ }^{\circ} \mathrm{C}$ for further 
use. The concentration of the cell membrane sample was quantified using a BCA protein kit according to the product instructions.

\section{Preparation of DMSN-DHA@BMECM NPs.}

DHA powder was dissolved in $5 \mathrm{~mL}$ of $50 \%$ DMSO by ultra-sonification to obtain varying concentrations of DHA solution $(0.2 \mathrm{mg} / \mathrm{mL}, 0.5 \mathrm{mg} / \mathrm{mL}, 1.0 \mathrm{mg} / \mathrm{ml}, 1.5$ $\mathrm{mg} / \mathrm{mL}, 2.0 \mathrm{mg} / \mathrm{mL})$. DMSN powder $(5 \mathrm{mg})$ was added and dispersed into each of the DHA solutions using ultra-sonification for $20 \mathrm{~min}$; then, the mixture was rotated for $24 \mathrm{~h}$ to load the drug into the pores of DMSN. Immediately after the loading process, $1 \mathrm{mg} / \mathrm{mL}$ DMSN-DHA was coated in with cell membrane by adding an equal volume of $1 \mathrm{mg} / \mathrm{mL}$ cell membrane into the resulting mixture and ultra-sonicating for $20 \mathrm{~min}$. Finally, the DMSN-DHA@BMECM NPs were washed with water and collected by centrifugation. SDS-PAGE was performed to verify the protein features of the obtained membrane. The specific protein markers, including ICAM and VCAM, were characterized by western blotting and SDS-PAGE analysis.

\section{Biodegradability and sustained drug release profile.}

The degradation behavior of the DMSN $(200 \mu \mathrm{g} / \mathrm{mL})$ was performed in a buffer that mimicked intracellular GSH concentrations $(\mathrm{GSH}, 10 \mathrm{mM})$ at $\mathrm{pH} 7.4,37{ }^{\circ} \mathrm{C}$. The DMSN was incubated with mouse serum to evaluate their stability in blood, using PBS buffer as a control. The samples were collected at 1, 3, and 7 days for TEM analysis to investigate morphological changes. DLS and zeta potential analyses were used to assess the change of the hydration radius and potential in PBS buffer. ${ }^{6}$

The DHA loading and releasing profiles were measured by HPLC equipment with 
a diode array detector (DAD). As DHA was very insoluble in water, DMSO, dimethylformamide (DMF), methanol, and acetonitrile were tested for the ability to dissolve DHA powder. The solvent for drug loading was 50\% DMSO (v/v), and 10\% methanol $(\mathrm{v} / \mathrm{v})$ was used for the drug-release test. The running condition was performed as follows: a $4.6 \mathrm{~mm} \times 250 \mathrm{~mm}$ reverse phase $\mathrm{C} 18$ column $(5 \mu \mathrm{m})$ was used as a filler, and acetonitrile/water (60:40) was the eluent phase with a flow rate of $0.8 \mathrm{~mL} / \mathrm{min}$. The UV/VIS absorption spectra were recorded at $210 \mathrm{~nm}$ wavelength, and the sample injection volume was $20 \mu \mathrm{L}$. All the processes were conducted at $25{ }^{\circ} \mathrm{C}$. The DHA peaks at 9.2 min were concentration-dependent, and a concentration range from $8 \mu \mathrm{g} / \mathrm{mL}$ to $2,000 \mu \mathrm{g} / \mathrm{mL}$ produced a linear relationship; the correlation coefficient $\left(\mathrm{R}^{2}\right)$ was up to 0.997 . The DHA loading efficiency (LE) and loading capacity (LC) were calculated by the following formula:

$$
\begin{aligned}
& \mathrm{LE}=\frac{\mathrm{MT}-\mathrm{MU}}{\mathrm{MT}} \times 100 \% \\
& \mathrm{LC}=\frac{\mathrm{MT}-\mathrm{MU}}{\mathrm{MN}+\mathrm{MM}} \times 100 \%
\end{aligned}
$$

Where MT was the total mass of DHA used for drug loading, and MU was the mass of unloaded DHA. MN was the mass of DMSN, and MM was the mass of the cell membrane in DMSN-DHA@BMECM.

To study DHA release efficiency, the samples were divided into two groups; (a) $10 \%$ methanol in PBS $(10 \mathrm{mM}, \mathrm{pH}=7.4)$, (b) $10 \%$ methanol in PBS $(10 \mathrm{mM}, \mathrm{pH}=$ 7.4) containing $10 \mathrm{mM}$ GSH. DMSN-DHA@BMECM (5 mg) was dissolved in $5 \mathrm{~mL}$ of (a) or (b) solution. Subsequently, $0.2 \mathrm{~mL}$ of the solution was sampled at the desired time points and was replaced with $0.2 \mathrm{~mL}$ buffer to maintain the total volume. The 
collected samples were centrifugal at $10,000 \mathrm{r} / \mathrm{min}$ for $10 \mathrm{~min}$ to separate the solids, and DHA content in the supernatant was analyzed using a HPLC spectrometer to determine the released DHA mass.

\section{In vitro hemolysis analysis.}

For the hemolysis study ${ }^{7}$,DHA, DMSN-DHA, and DMSN-DHA@BMECM were investigated at high $(1.758 \mu \mathrm{M} / \mathrm{L})$, medium $(175.8 \mathrm{nM} / \mathrm{L})$, and low $(17.58 \mathrm{nM} / \mathrm{L})$ concentrations. Blood from healthy mice and $P b A$-infected mice was centrifuged at $1500 \mathrm{r} / \mathrm{min}$ for $10 \mathrm{~min}$ and washed three times with normal saline to obtain RBCs. $50 \%$ hematocrit (Hct) was obtained by adding normal saline to the cells. Normal saline $(570 \mu \mathrm{L})$ containing $30 \mu \mathrm{l}$ cell suspension was used as a negative control $(0 \%$ hemolysis). The positive control (100\% hemolysis) was $30 \mu \mathrm{l}$ of cells diluted with $570 \mu \mathrm{L}$ ultrapure water $(18.3 \mathrm{~m} \Omega)$, which was used to lyse RBCs in a hypotonic medium. Varying concentrations of NPs were then added to the cell suspension, and each experimental condition (controls, each DHA-, DMSN-, and DMSN@BMECM-treatment) was performed in triplicate wells. The samples were treated with near-infrared light $(650 \mathrm{~nm})$ for $10 \mathrm{~min}$ and then incubated at $37^{\circ} \mathrm{C}$ for 3 $\mathrm{h}$ in a shaker. Next, the samples were centrifuged at $1500 \mathrm{rpm}$ for $10 \mathrm{~min}$, and then the absorbance at $540 \mathrm{~nm}$ was measured using a UV/VIS spectrometer. A hemolysis ratio (A\%) of less than $5 \%$ was regarded as nontoxic. The percentage of hemolysis was calculated using the following equation:

$$
\text { Hemolysis }(\%)=\frac{\text { Atest }- \text { Aneg }}{\text { Apos }- \text { Aneg }} \times 100 \%
$$

Where $\mathrm{A}_{\text {test }}$ was the absorbance of DHA-DMSN or DMSN@BMECM sample, $\mathrm{A}_{\text {pos }}$ 
was the absorbance of the positive control, and $\mathrm{A}_{\text {neg }}$ was the absorbance of negative controls.

\section{MTT test.}

Bend. 3 cells were incubated in a DMEM medium containing $1 \%$ antibiotics and $10 \%$ (v/v) FBS at $37^{\circ} \mathrm{C}$. The cell density was adjusted to $1 \times 10^{4}$ cells per well; then, cells were seeded into a 96-well plate and cultured for $24 \mathrm{~h}$ at $37{ }^{\circ} \mathrm{C}$. The media was changed to media containing bare DMSN and DMSN@BMECM. After $4 \mathrm{~h}$ incubation, the media were replaced with a fresh medium containing $0.5 \mathrm{mg} / \mathrm{mL}$ MTT reagent and incubated for another $4 \mathrm{~h}$. The media was then replaced by $200 \mu \mathrm{L}$ DMSO and gently shaken for $15 \mathrm{~min}$ at room temperature before absorbance at 490 $\mathrm{nm}$ was measured using a microplate reader. The cell viability was calculated according to the following equation ${ }^{8}$ :

$$
\text { Cell viability }(\%)=\frac{\text { OD } 490-\text { Sample }}{\text { OD } 490-\text { Control }} \times 100 \%
$$

RBCs and infected RBCs endocytosis and targeting assay.

Flow cytometry (FCM) was performed to test the endocytosis ability of the infected RBCs and normal $\mathrm{RBCs}^{9,}{ }^{10}$. To test the endocytosis between mice BMECM covered nanodrug and mice RBCs/iRBCs, fresh peripheral blood from healthy and $P b A$-infection $C 57 B L / 6 N$ mice was centrifuged for $5 \mathrm{~min}$ at 3,000 rpm to remove the plasma, and the remaining residues were washed twice with normal saline. Alsever's solution was added to suspend the cells; then cells were counted using a blood cell counting plate. Notably, "Normal" represented the blood RBCs of healthy mice, and “parasitemia” represented infected mice's blood, which contained about 5\% infected 
RBCs and 95\% $\mathrm{RBC}^{2} .1 \times 10^{6} \mathrm{RBCs}$ and infected $\mathrm{RBCs}$ were added to each tube and mixed with either normal saline, $50 \mu \mathrm{g} / \mathrm{mL}$ Cy5-labeled DMSN, or DMSN@BMECM. After shaking at $40 \mathrm{rpm}$ at $37{ }^{\circ} \mathrm{C}$ for $1,2,4$, or $8 \mathrm{~h}$, the cells were centrifuged at 3,000 rpm for $5 \mathrm{~min}$ and washed twice with normal saline buffer to remove any residual NPs. All the samples were then suspended in Alsever's solution and analyzed by flow cytometry. The fluorescence of Cy5 staining cells falls into the R675 (APC) channel (excitation $640 \mathrm{~nm} / \mathrm{emission} 675 \mathrm{~nm}$ ) in the NovoCytemachine. Experiments were repeated three times and analyzed by NovoExpress software.

To further confirm the endocytosis action between hBMECM covered nanodrug and human iRBCs, fresh healthy or P. falciparum-infection human whole blood (with heparin sodium as an anticoagulant) was prepared as follow: $1 \mu \mathrm{L}$ healthy human RBCs and infected RBCs (7.7\% parasitemia) were resuspended in $100 \mu \mathrm{L}$ PBS with 1\% volume. MSN-Cy3 and MSN-Cy3@hBMECM samples were diluted to $50 \mu \mathrm{g} /$ $\mathrm{mL}$ and $100 \mu \mathrm{g} / \mathrm{mL}$ by PBS, respectively. Added $2 \mu \mathrm{L}$ RBCs or P. falciparum-iRBCs into $100 \mu \mathrm{L}$ of MSN-Cy3 or MSN-Cy3@hBMECM buffer, then they were incubated at $37{ }^{\circ} \mathrm{C}$ for $1 \mathrm{~h}$ and $3 \mathrm{~h}$ under dark. The fluorescence of Cy3 staining cells falled into the PE channel in the NovoCytemachine and was analyzed by NovoExpress software. The binding efficiency for iRBCs was calculated as follow:

$$
\text { Binding }(\%)=\frac{\mathrm{R} 2(\text { Parasitemia })-\mathrm{R} 2(\text { Normal })}{\text { Parasitemia } \%} \times 100 \%
$$

Where R2 was the percent of PE region, which was selected by HE (Hydroethidine) and TO (Thiazole orange) dyes for iRBCs as the positive control (Figure S8), the parasitemia of iRBCs was $7.7 \%$. 
The self-target ability of DMSN@BMECM to the source brain microvascular endothelial cells.

The self-targeting ability of the source cell line was investigated using bEnd. 3 cells as mice brain cell model and primary cultured human microvascular endothelial cells as human brain cell model. Mouse embryonic fibroblasts cells (3T3) were used as a compare sample for bEnd. 3 cells. Membrane from healthy human dermal fibroblasts (NHDF), human malignant glioblastoma cell (U87MG), human umbilical vein endothelial cell (HUVEC), and human normal RBC membrane were prepared in the same way of bEnd.3 cells membrane mentioned above. For CLSM, each cell line was incubated in confocal dishes at a density of $1 \times 10^{4}$ cells per dish. After $24 \mathrm{~h}$, the DMEM medium was replaced with $1 \mathrm{~mL}$ Opti-MEM medium containing $50 \mu \mathrm{g} / \mathrm{mL}$ dye (FITC or Cy3) loaded DMSN or DMSN@ membrane NPs. After 4 h, cells were observed with CLSM and analyzed using Image J software (Version 1.50i). The nucleus was dyed with $1 \mathrm{~mL}$ DMEM containing $10 \mu \mathrm{L}$ Hoechst 33342 dye and kept at $37^{\circ} \mathrm{C}$ for $15 \mathrm{~min}$ before CLSM imaging.

For FCM test, $5 \times 10^{5}$ hBMECs incubated with $50 \mu \mathrm{g} / \mathrm{mL}$ Cy5-loaded DMSN@hBMECM, DMSN@NHDFM,DMSN@U87M, DMSN@HUVECM, and DMSN@hRBCM in Opti-MEM medium at $37{ }^{\circ} \mathrm{C}$ for $2 \mathrm{~h}$. Then, wash twice with PBS buffer and test in NovoCytemachine. The cells containing Cy5-loaded NPs fell into the APC channel and were analyzed by NovoExpress software.

\section{Assessment of BBB permeability.}

The pathological vascular injury of the BBB was reflected by the leakage of plasma 
proteins across the $\mathrm{BBB}$ into the cerebral parenchyma. The vascular marker dye Evans blue was used to analyze BBB integrity. On day 7 post-infection, $200 \mu \mathrm{L}$ of $0.5 \%$ of Evans blue solution was intravenously injected into mice. After 2 hours, 0.9 $\%$ saline was perfused through the heart. Brains were removed rapidly, weighed, and homogenized in $1 \mathrm{~mL}$ PBS. The samples were centrifuged at 1,000 g, and acetone was added to the supernatant (supernatant: acetone $=3: 7$ ). The sample was incubated at room temperature to extract Evans blue dye for $12 \mathrm{~h}$ in capped tubes; tubes were then centrifuged at $1,000 \mathrm{~g}$ for $15 \mathrm{~min}$. The absorbance was measured using a spectrophotometer at $620 \mathrm{~nm}$, and the amount of Evans blue staining in each group was calculated by a standard curve.

\section{Parasitemia activity.}

$P b A$-infected mice $(\mathrm{n}=6)$ were treated with either normal saline (untreated group), DHA (3 mg/kg), DMSN-DHA (containing $3 \mathrm{mg} / \mathrm{kg}$ DHA and $6 \mathrm{mg} / \mathrm{kg}$ DMSN), or DMSN-DHA@BMECM (containing 3 mg/kg DHA and 6 mg/kg DMSN@BMECM) given by intravenous injection at days $3,4,5,6$, and 7 post-infection. Parasitemia in each group was monitored on days 3, 5, 7, 9, 12, and 15 after $P b A$-infection and was determined in thin blood smears under an immersion optical microscope at $1,000 \times$ magnifications. Parasitemia was quantified by counting the number of parasitized RBCs in at least 1,000 RBCs.

\section{Histological analysis and deposited hemozoin analysis.}

The neurological symptoms of ECM usually occur from day 4 to day 8 after $P b A$-infection, depending on the individual animals and the population ${ }^{1}$. Once 
$P b A$-infected mice presented ECM evidence (on day 8), two mice from each group were euthanized for histological analysis. Mice were euthanized by $\mathrm{CO}_{2}$ narcosis and cervical dislocation. Mice without symptoms of cerebral malaria were euthanized on day 10. The brains, livers, and spleens were collected immediately after euthanasia and washed three times in cold PBS to remove the blood. The brains, livers, and spleens were then fixed with $4 \%$ paraformaldehyde for $24 \mathrm{~h}$ and embedded in paraffin.

Examination of microvascular leakage and obstruction was made in 4-mm-thick horizontal sections stained with hematoxylin-eosin (H\&E) or Prussian blue. $\mathrm{Hz}$ accumulation was measured in sections of HE-stained liver and spleen. The percentage of $\mathrm{Hz}$ was calculated based on the following equation:

$$
\mathrm{Hz}(\%)=\frac{\mathrm{Hz} \text { area }}{\text { Field area }} \times 100 \%
$$

Where $\mathrm{Hz}$ area was the area of deposited hemozoin, Field area was the area of the whole image taken by the software of Olympus cellSens standard 1.13.

To analysis the $\mathrm{RePu}$ areas in Figure S25, the grey pictures were acquired from Image $\mathrm{J}$ software (version $1.50 \mathrm{i}$, USA) by setting the threshed, representing the interesting region of the $\mathrm{RePu}$ area. Finally, the area data of the $\mathrm{RePu}$ was generated by the Image $\mathrm{J}$ software (Table S2).

\section{Transcriptome sequencing and analysis.}

On day 8 post-infection, mice were anesthetized as previously described. Brain tissue was quickly harvested and washed in cold normal saline, frozen in liquid nitrogen, and kept at $-80{ }^{\circ} \mathrm{C}$ until use. RNA was extracted using TRIzol reagent according to 
the manufacturer's instructions (Invitrogen, USA). RNA purity, integrity, degradation, and contamination were all monitored before the experiment. A total of $3.0 \mu \mathrm{g}$ RNA per sample was used as input material. A NEBNext Ultra RNA library prep kit for Illumina (NEB, USA) was used to generate sequencing libraries. Each library was sequenced on an Illumina HiSeq platform (San Diego, CA, United States). Raw reads were acquired through in-house Perl scripts. Removing reads containing adapter, ploy-N, and low-quality reads from the raw reads resulted in high-quality reads for downstream analyses ${ }^{11}$. An index of the reference genome and paired-end clean reads were built using Hisat v2.0.5 $5^{12}$ The read numbers mapped to each gene were analyzed using featureCounts v1.5.0-p3 software ${ }^{13}$. DEGs were identified according to an adjusted $p$-value $<0.05$ by DESeq and $\log 2$ fold-change $\geq$ 2.0 gene ontology, and KEGG pathway enrichment analysis of DEGs was implemented by the methods of Kanehisa and Young ${ }^{14,15}$.

Statistical analysis. Data were analyzed using the Statistical Package for Social Sciences (SPSS Inc., USA). Survival analyses were performed by the log-rank (Mantel-Cox) test. All graphs were made using GraphPad Prism 5 software (version 5.01, USA) and Origin 8.0. Results were considered statistically significant when the p-value was less than $0.05 .{ }^{*} p<0.05,{ }^{* *} p<0.01,{ }^{* * *} p<0.001$. The histological analysis and $\mathrm{Hz}$ calculation images were photographed and evaluated by cellSens standard software (Olympus, Japan) and Image J software (version 1.50i, USA). Each experiment was repeated three times. 

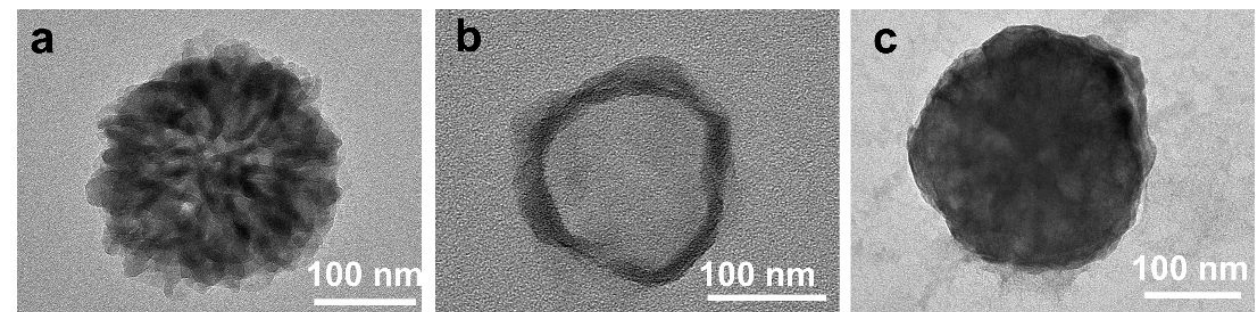

Figure S1. TEM characterization of magnified (a) dendritic DMSN, (b) pure bEnd.3 cell membrane, and (c) cell membrane coated DMSN; that was, DMSN@BMECM.

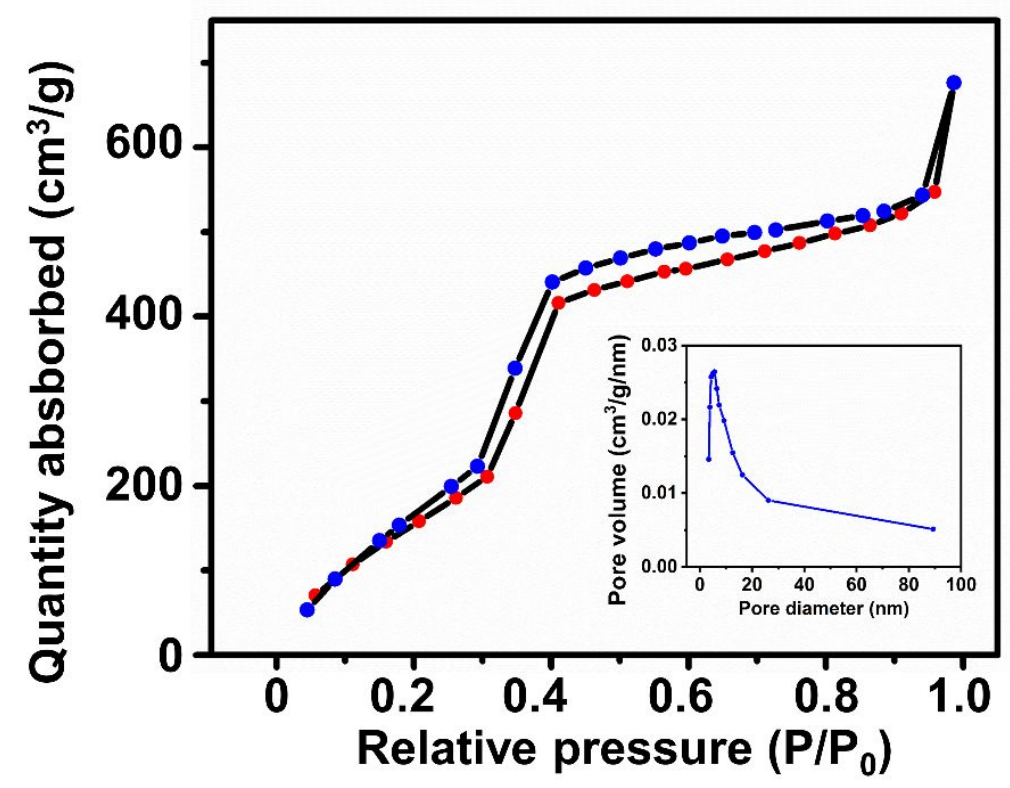

Figure S2. A nitrogen absorption-desorption isotherm and the corresponding pore-size distribution of DMSN (inset). 


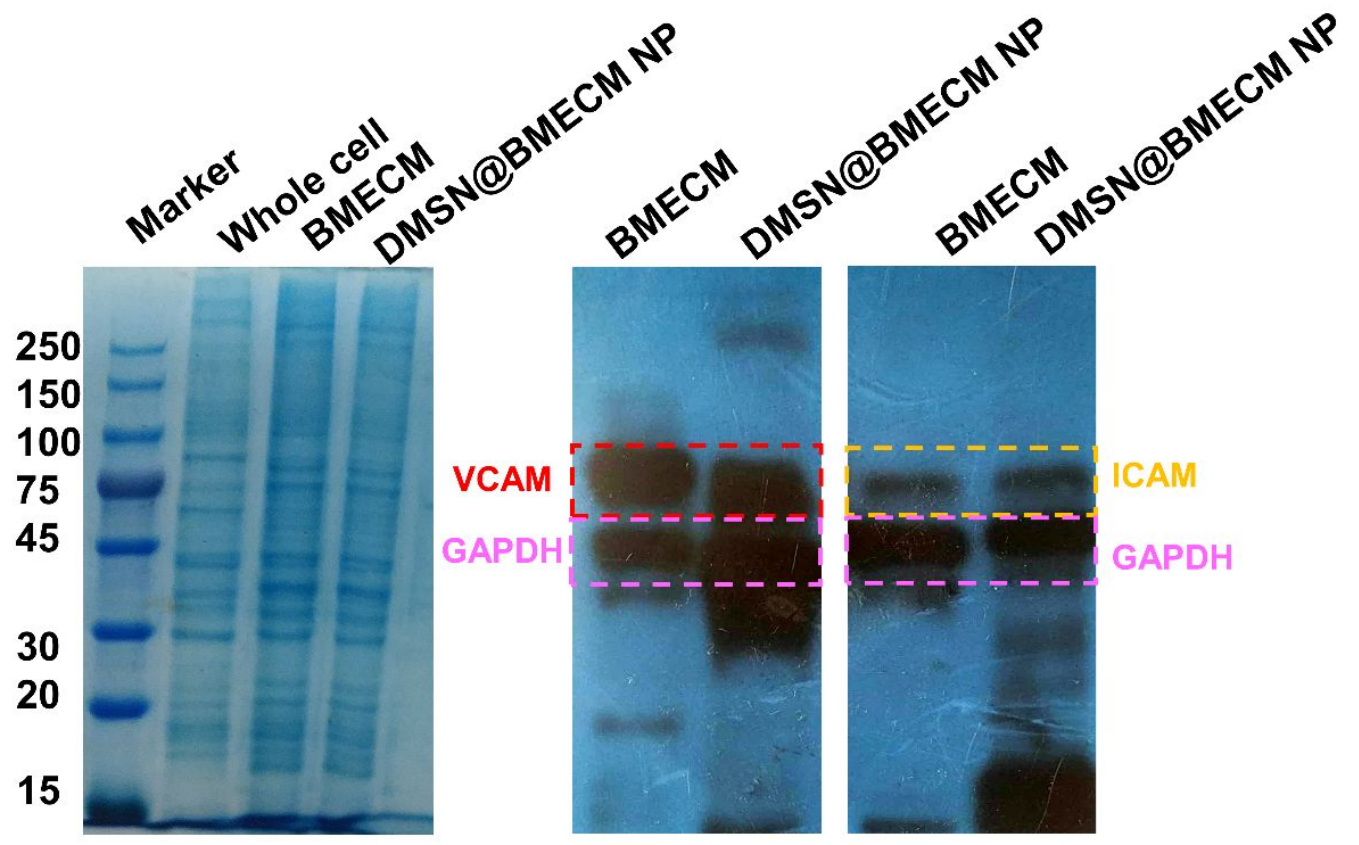

Figure S3. Original images of data from SDS-PAGE and western blot experiments.

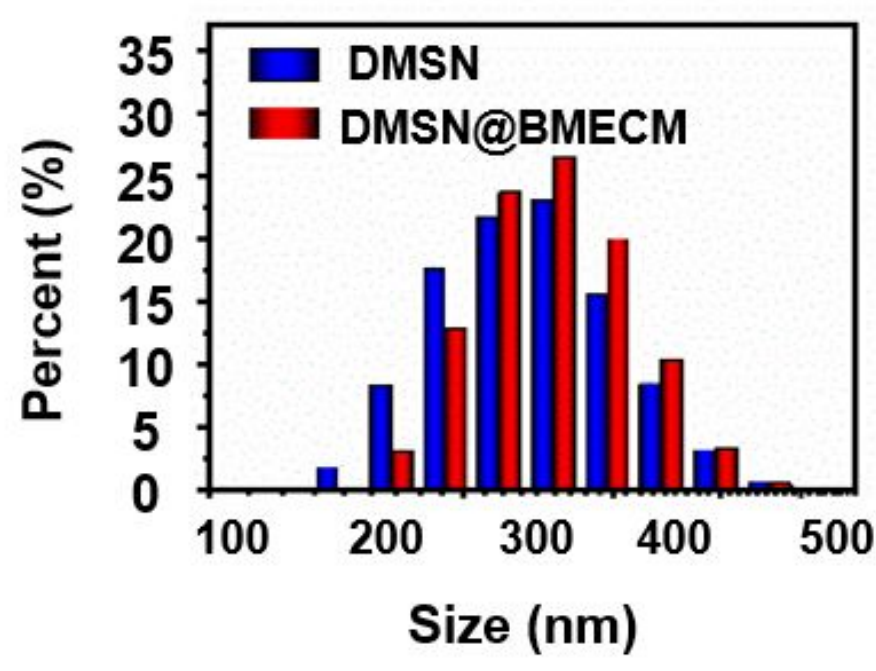

Figure S4. DLS of DMSN and DMSN@BMECM. The hydrodynamic size of the DMSN was about $270 \mathrm{~nm}$, which increased to $290 \mathrm{~nm}$ after DMSN was coated with the BMECM. Each experiment was repeated three times. 


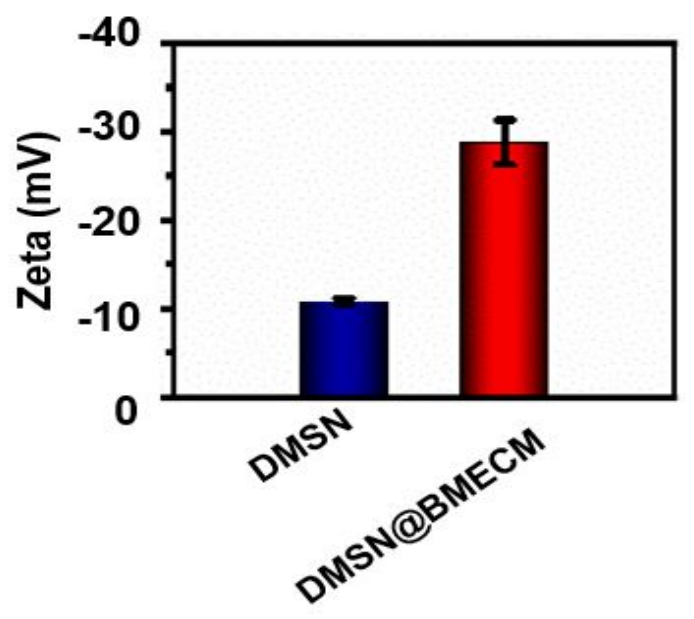

Figure S5. Zeta potential measurement analyses of DMSN and DMSN@BMECM. The surface zeta potential decreased from $-12 \mathrm{mV}$ to $-29 \mathrm{mV}$ after the membrane-coating process. Each experiment was repeated three times.

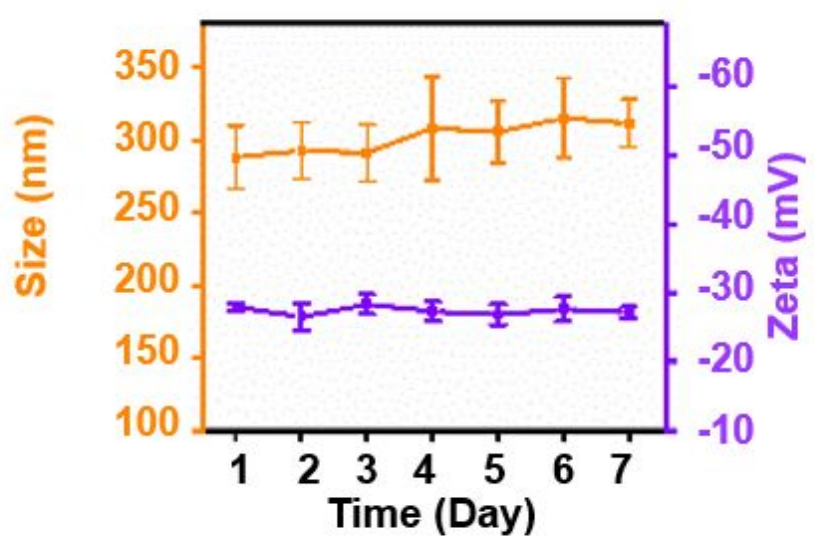

Figure S6. Stability analysis of DMSN-DHA@BMECM in PBS buffer for 7 days. 


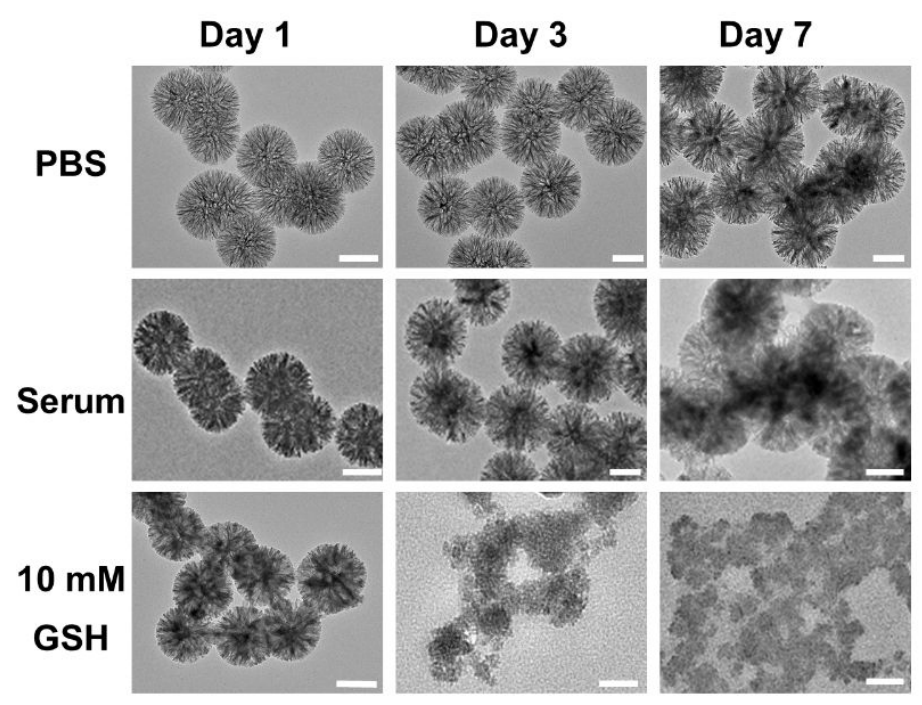

Figure S7. TEM degradation images of DMSNs (200 $\mu \mathrm{g} / \mathrm{mL})$ in PBS (top), serum (middle) and $10 \mathrm{mM}$ GSH buffer (bottom) at various times. Scale bar: $100 \mathrm{~nm}$.

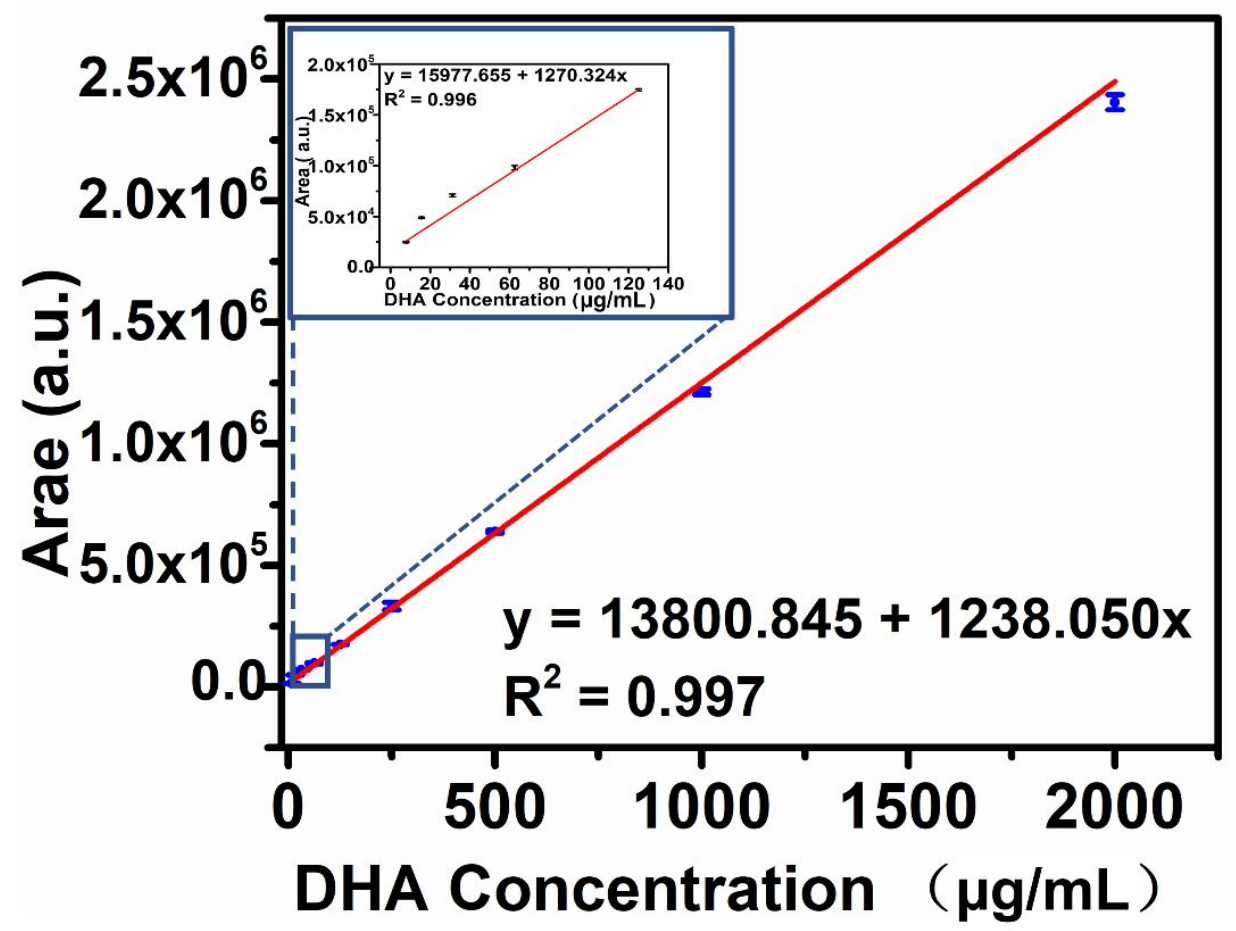

Figure S8. DHA standard curve. Each experiment was repeated three times. 
$a^{\mathrm{mAl}}$

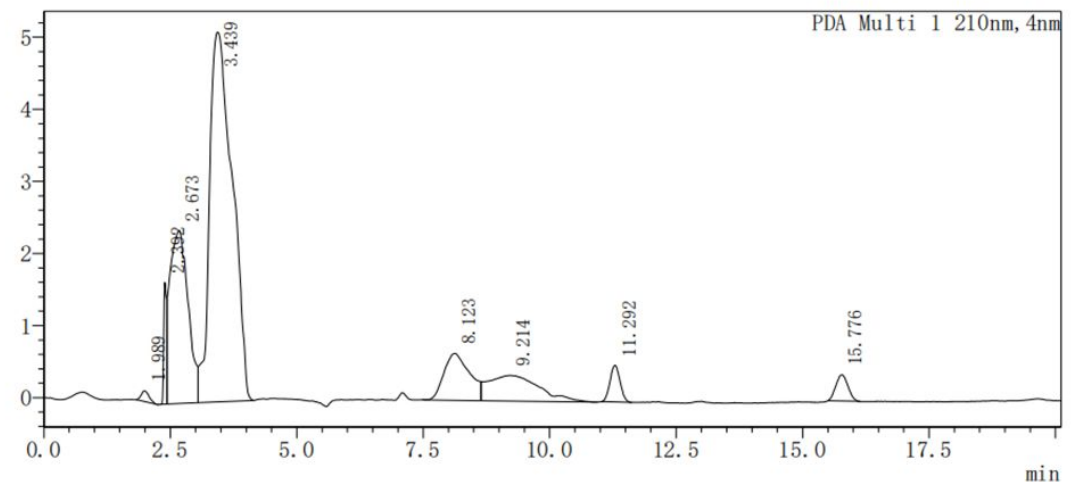

b $\mathrm{mAU}$

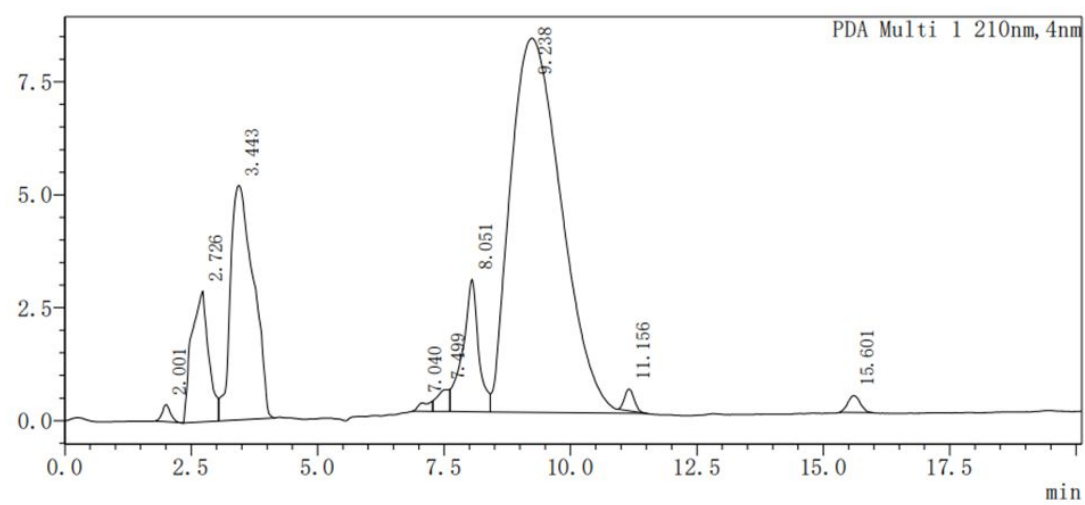

C $\mathrm{mAU}$

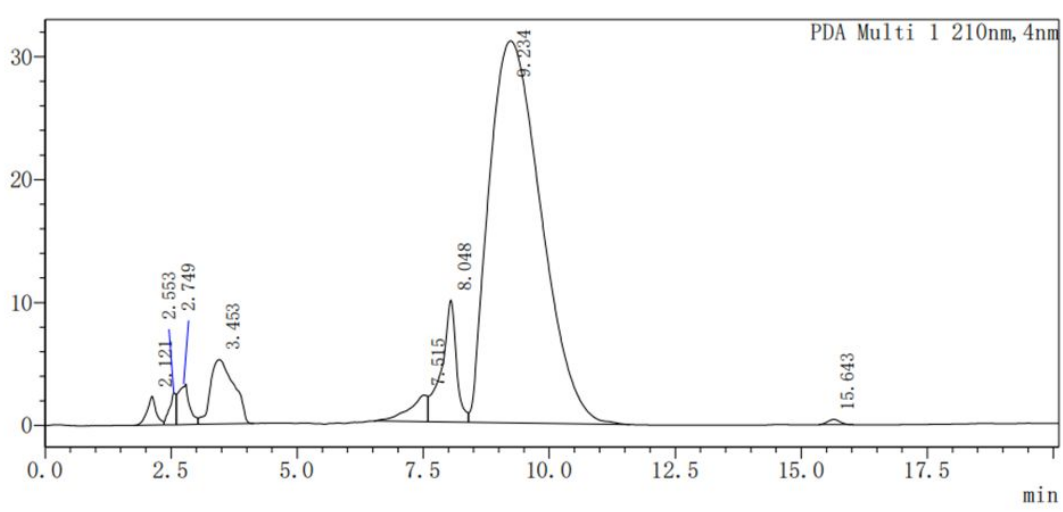

Figure S9. Representative images of HPLC analysis of DHA standards. (A) 0.008 $\mathrm{mg} / \mathrm{mL}$ DHA, (B) $0.5 \mathrm{mg} / \mathrm{mL}$ DHA and (C) $2.0 \mathrm{mg} / \mathrm{mL}$ DHA. The retention time of the DHA peak was approximately $9.2 \mathrm{~min}$. The height and area of the DHA peaks were related to the concentration of the sample. 


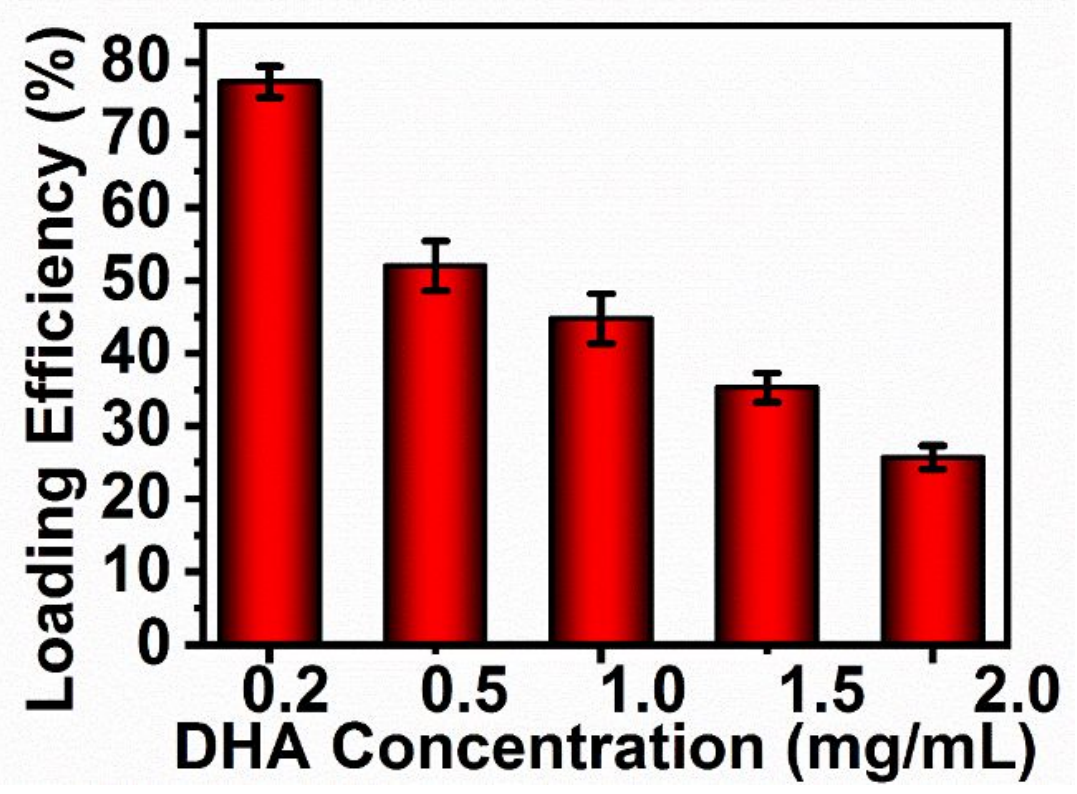

Figure S10. DHA loading efficiency. Each experiment was repeated three times. 


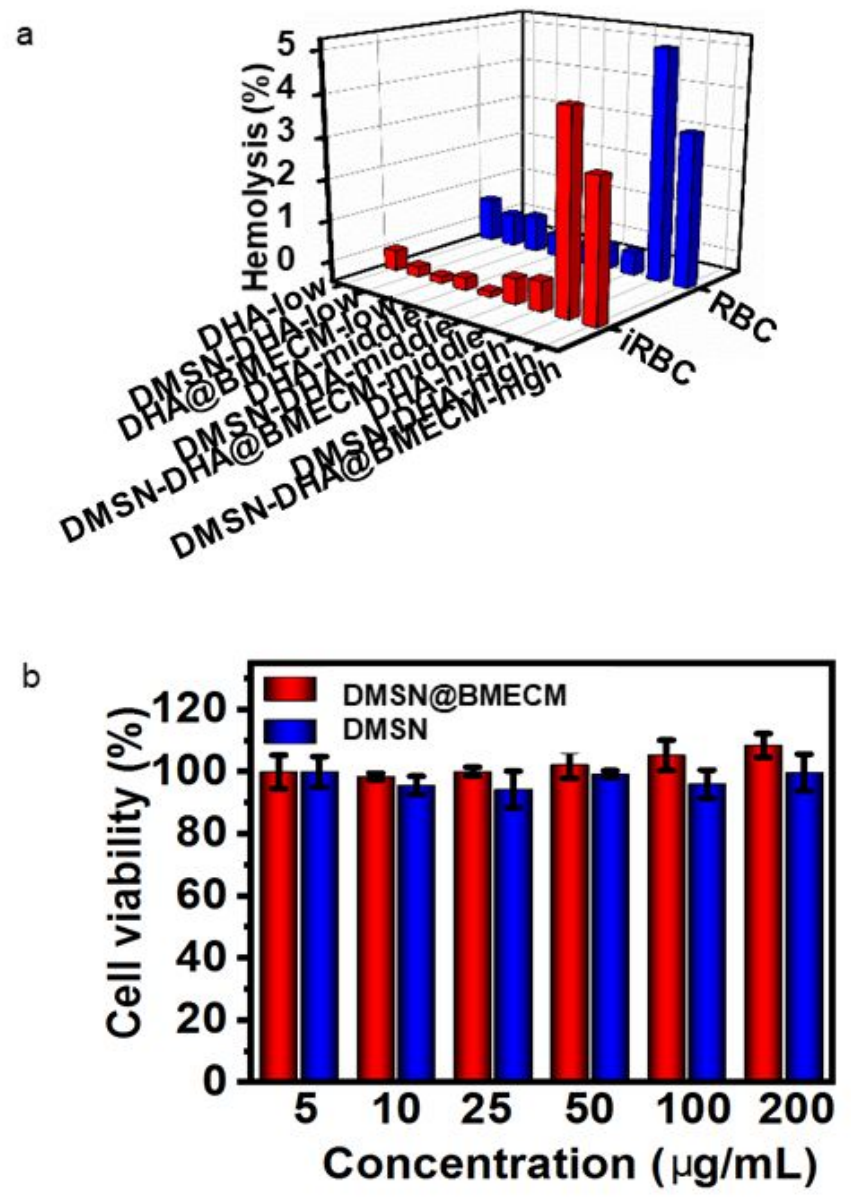

Figure S11. In vitro cytotoxicity of DMSN and DMSN@BMECM. (a) Hemolysis analysis of low $\left(\mathrm{C}_{\mathrm{DMSN}}=10 \mathrm{ng} / \mathrm{mL}, \mathrm{C}_{\mathrm{DHA}}=5 \mathrm{ng} / \mathrm{mL}\right)$, medium $\left(\mathrm{C}_{\mathrm{DMSN}}=100 \mathrm{ng} / \mathrm{mL}\right.$, $\left.\mathrm{C}_{\mathrm{DHA}}=50 \mathrm{ng} / \mathrm{mL}\right)$ and high $\left(\mathrm{C}_{\mathrm{DMSN}}=1 \mu \mathrm{g} / \mathrm{mL}, \mathrm{C}_{\mathrm{DHA}}=0.5 \mu \mathrm{g} / \mathrm{mL}\right)$ concentrations of NPs incubated with RBCs or infected RBCs. Hemolysis of RBCs and iRBCs induced by DHA, DMSN-DHA NPs, DMSN-DHA@BMECM was less than 5\% of the total cell count in low, medium, and high concentrations of NPs. (b) The MTT test was used to measure cell viability at varying concentrations of DMSN and DMSN@BMECM. MTT experiments demonstrated that the viability of bEnd.3 cells in the presence of DMSN-DHA@BMECM was slightly higher than the viability in the presence of DMSN at all concentrations of NPs, indicating that BMECM coating improved the biocompatibility of the NPs. The number of repetitions for each specimen was 3; the error bars indicate the standard deviation. Each experiment was repeated three times. 

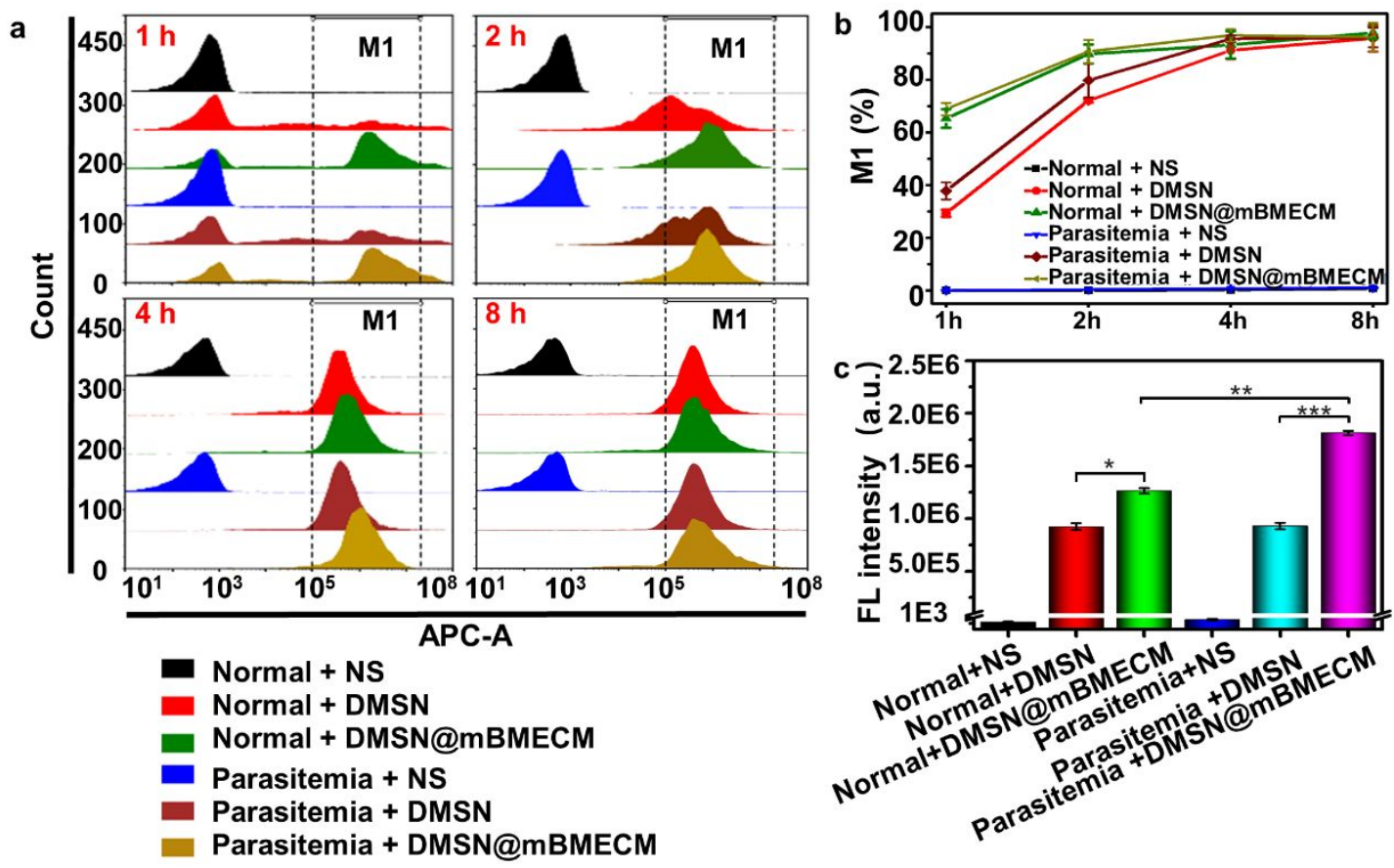

Figure S12. The binding ability of mice BMECM covered Nano-vector (DMSN@mBMECM) towards mice iRBCs induced by $P$. berghei ANKA $(P b A)$ in C57BL/6N Mice model.

(a) Representative images of flow cytometry of DMSN and DMSN@BMECM incubated with normal mice blood $(100 \%$ RBCs) or 5\% parasitemia-infected blood (5\% infected RBCs and 95\% RBCs) at different times. Normal saline (NS) was used as a control. DMSN@BMECM and DMSN $(50 \mu \mathrm{g} / \mathrm{mL})$ were incubated with normal RBCs and infected RBCs (5\% parasitemia was 95\% normal RBCs plus 5\% iRBCs) for $1,2,4$, and $8 \mathrm{~h}$ at $37^{\circ} \mathrm{C}$. by counting 10000 cells, the M1 region was determined by the fluorescent area of the cells that engulfed Cy5-loaded NPs. The peak area of the M1 region increased significantly when the incubation time was increased, indicating increased internalization of Cy5-loaded NPs. (b) A graph of the percentage of cells in the M1 region in (a) at different incubation times. The M1 percentage curve illustrated that DMSN@mBMECM entered the cells faster than DMSN NPs, indicating that BMECM coating promoted cellular adhesion and internalization, especially at 1 and $2 \mathrm{~h}$ timepoints. More than $90 \%$ of cells contained fluorescent NPs after $4 \mathrm{~h}$ of incubation. (c) The fluorescence intensity of different groups at $4 \mathrm{~h}$ incubation. The fluorescence intensity of both the normal and 5\% 
parasitemia-infected RBCs containing DMSN@mBMECM was higher than that of normal and 5\% parasitemia-infected RBCs incubated with DMSN NPs. Notably, the fluorescence intensity of infected RBCs incubated with DMSN@mBMECM was 1.4 times higher than that of normal RBCs incubated with DMSN@mBMECM. This result demonstrated that DMSN@mBMECM traped and detained parasite-infected RBCs, suggesting that a therapeutic platform containing DMSN@mBMECM might have an enhanced therapeutic effect towards infected RBCs. The number of repetitions for each specimen was 3; the error bars indicate the standard deviation. Each experiment was repeated three times.

a

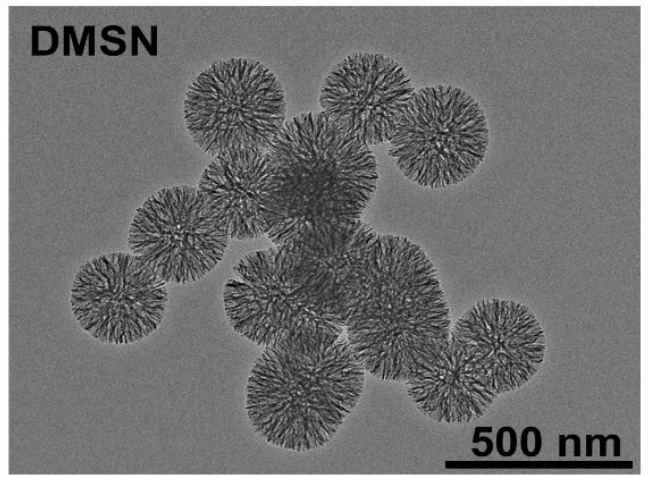

C

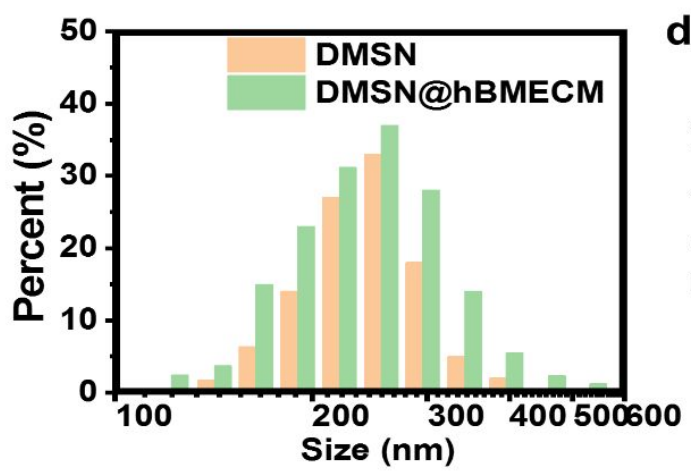

b DMSN@hBMEGM

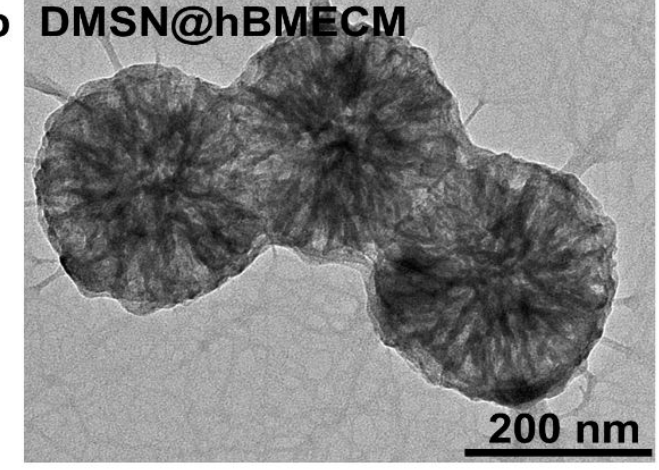

d

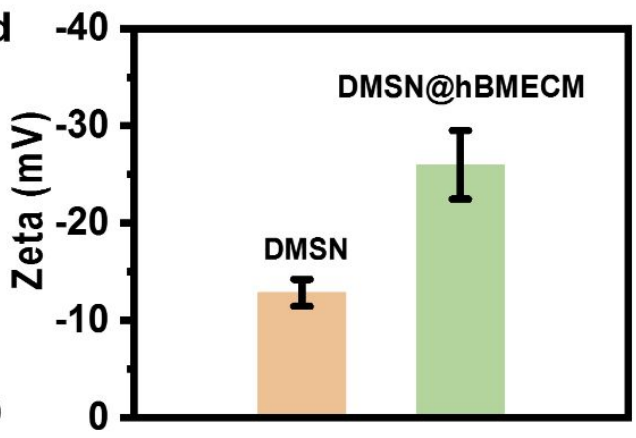

Figure S13. Characteristics of DMSN@hBMECM. (a) TEM image of DMSN and

(b) DMSN@hBMECM.

(c) DLS and

(d) zeta potential of DMSN and

DMSN@hBMECM. Each experiment was repeated three times. 


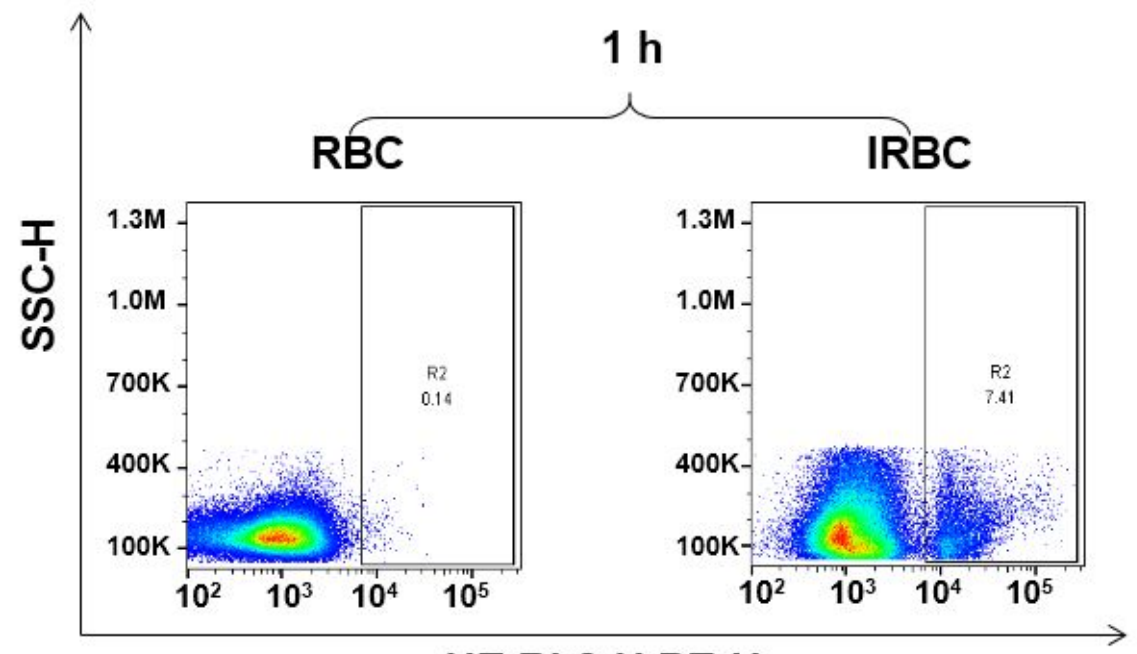

HE BL2-H PE-H

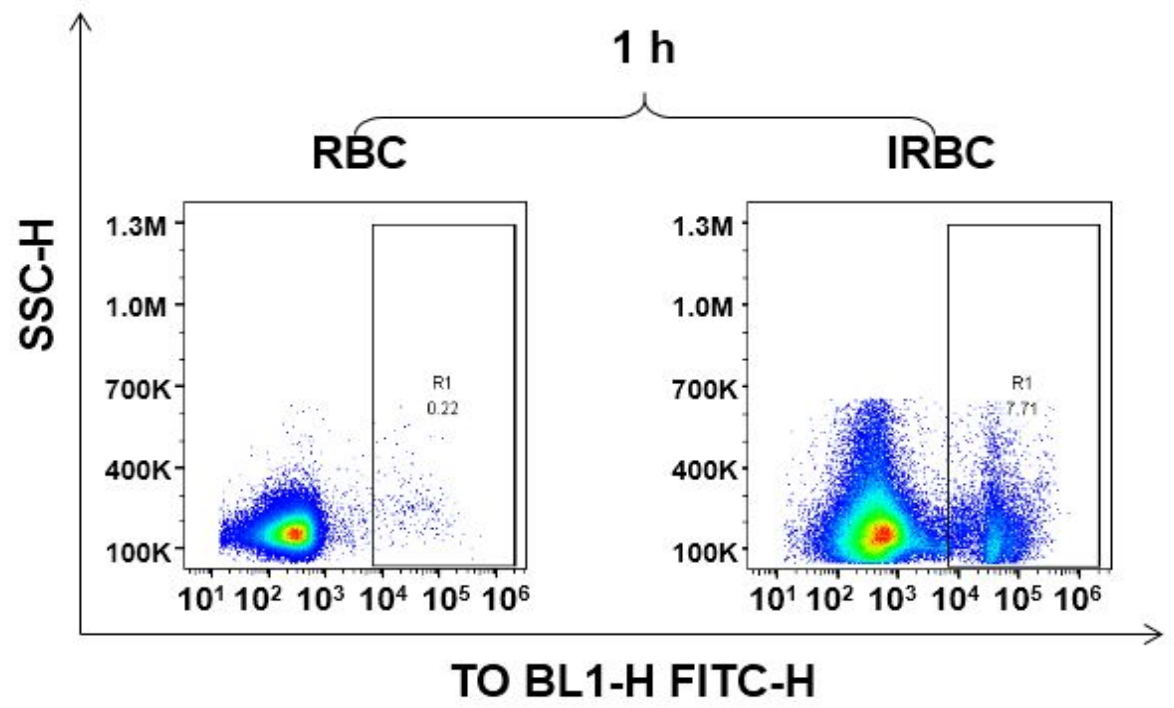

Figure S14. Positive control (HE and TO) for the flow cytometer test. Each experiment was repeated three times. 

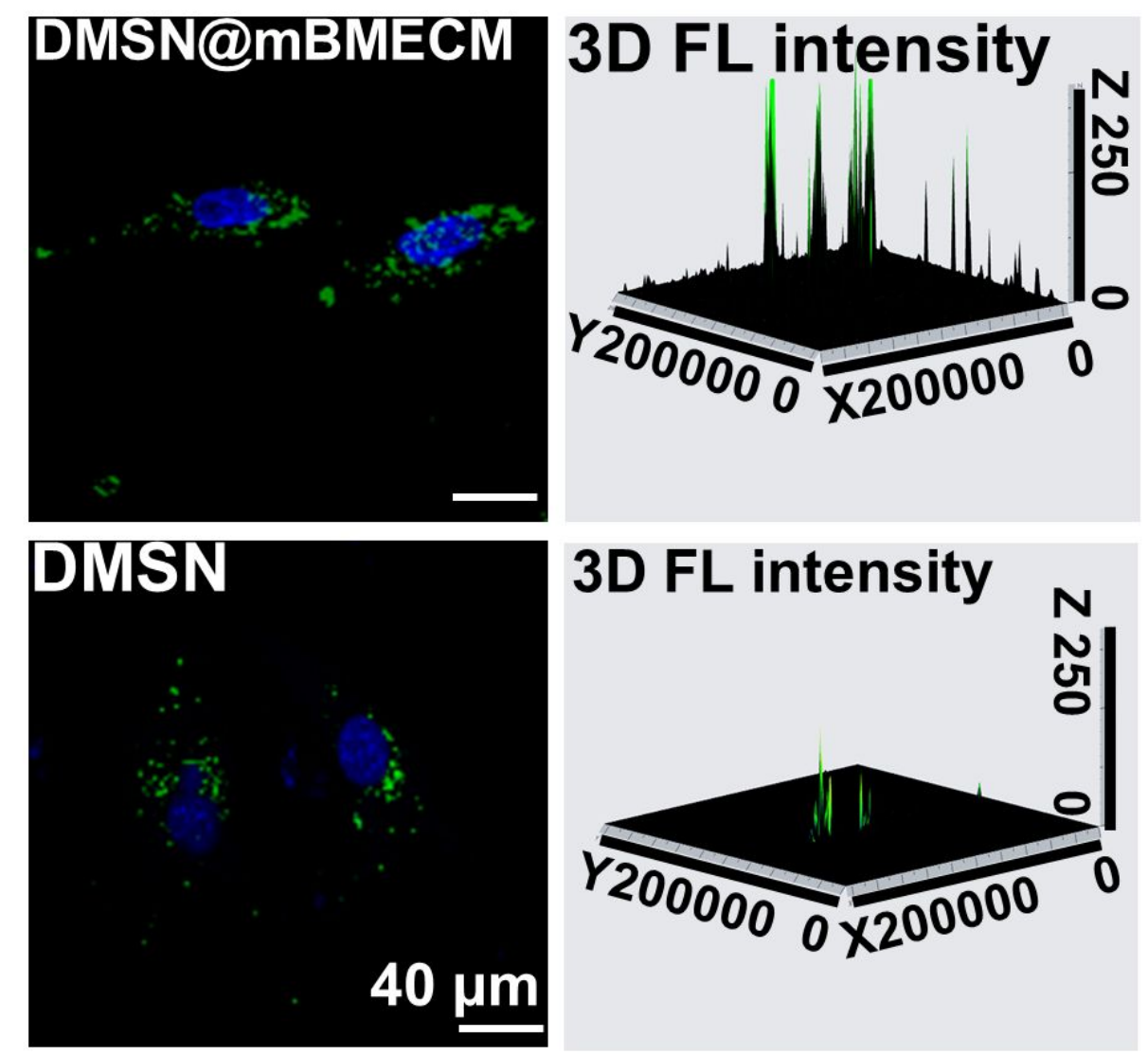

Figure S15. Typical CLSM images of bEnd.3 cells incubated with FITC-loaded DMSN@mBMECM or DMSN for 4 h. The 3D fluorescent intensity images of FITC were built and analyzed using ZEN 2012 software (Zeiss, Germany). Scale bars: 40 $\mu \mathrm{m}$. Each experiment was repeated three times. 


\section{MBMECM DMSN Merge 3D intensity}

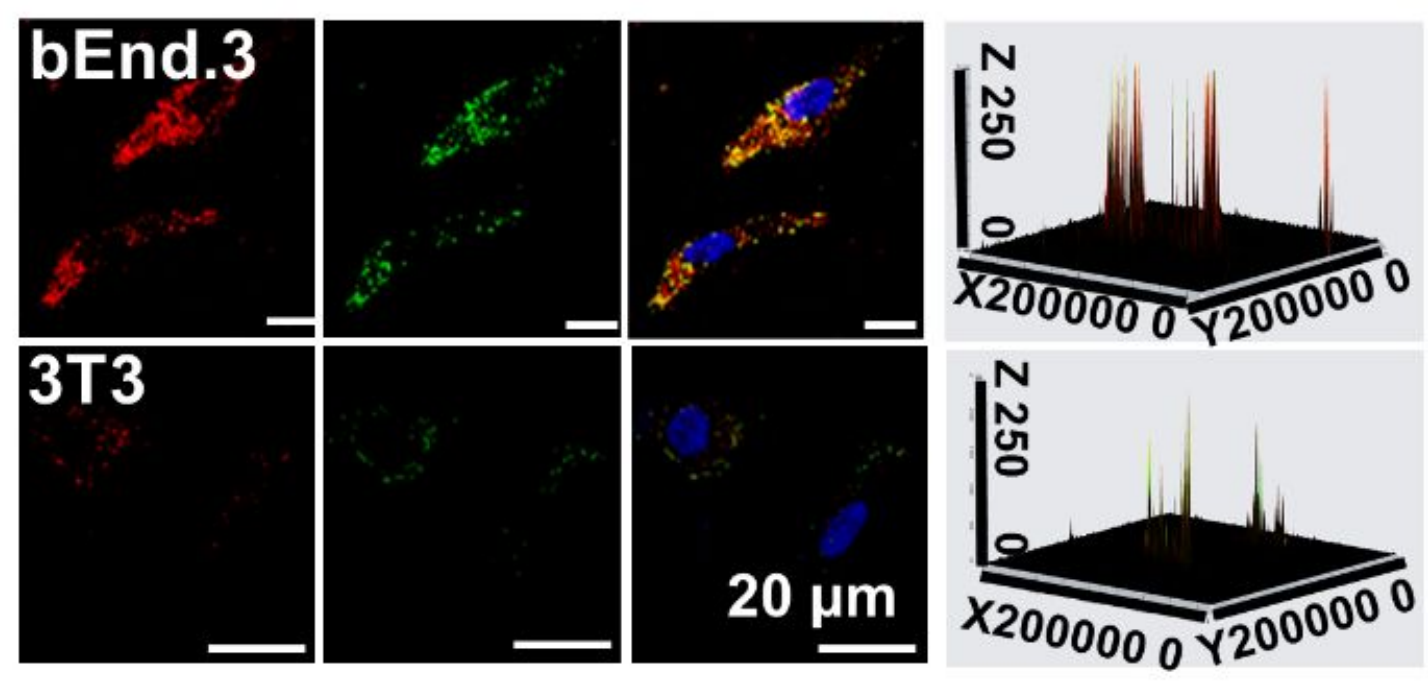

Figure S16. CLSM images of fluorescent DMSN@mBMECM incubated with bEnd.3 cells (top) and $3 \mathrm{~T} 3$ cells (bottom) for $4 \mathrm{~h}$. The mouse cell membrane (mBMECM) portion of the NPs was pre-strained with Dil dye, and the DMSN vectors were dyed with FITC. Scale bar: $20 \mu \mathrm{m}$. Each experiment was repeated three times. 


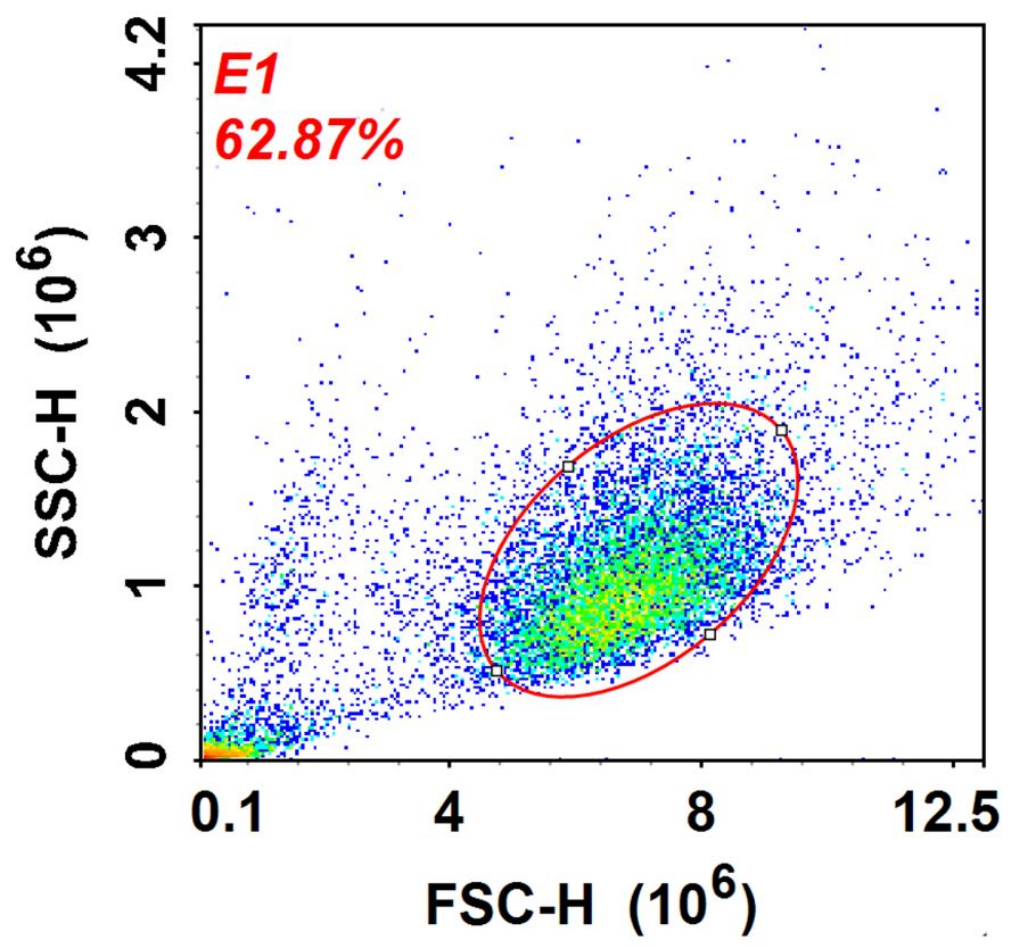

Figure S17. FCM E1 region collected by PBS treated human brain microvascular endothelial cells. Each experiment was repeated three times. 


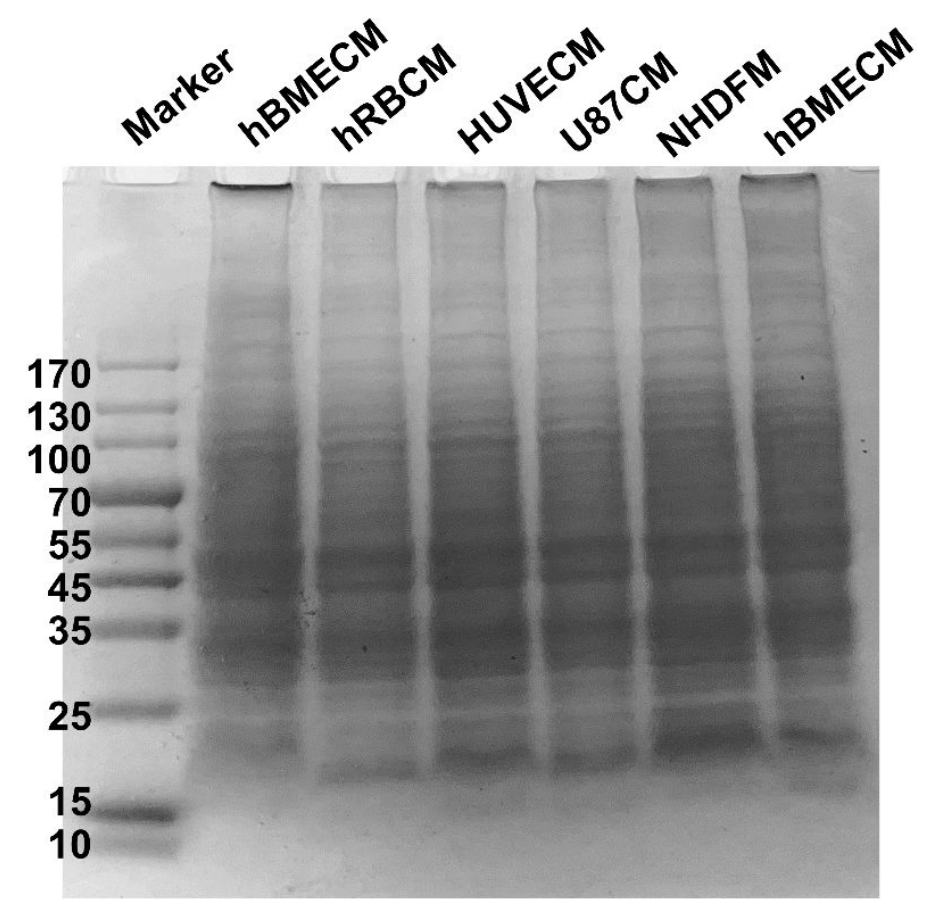

\section{ICAM-1 $-20 \mathrm{kDa}$}

\section{Actin $42 \mathrm{kDa}$}

Figure S18. SDS-PAGE electrophoresis and western blot analysis of the different human cell membranes. Each experiment was repeated three times. 


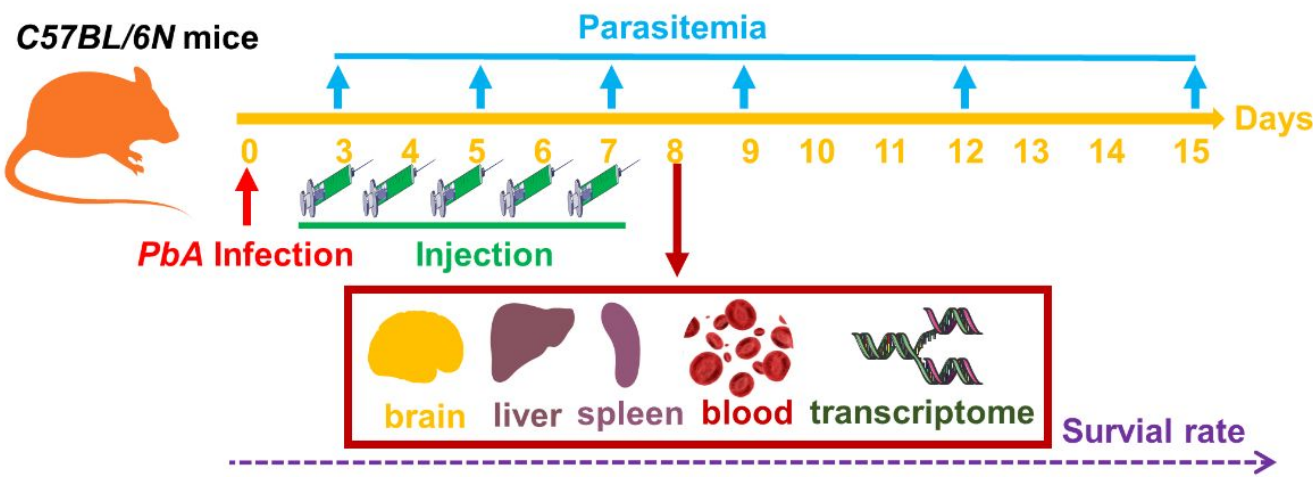

Figure S19. Flow charts of animal experiments 


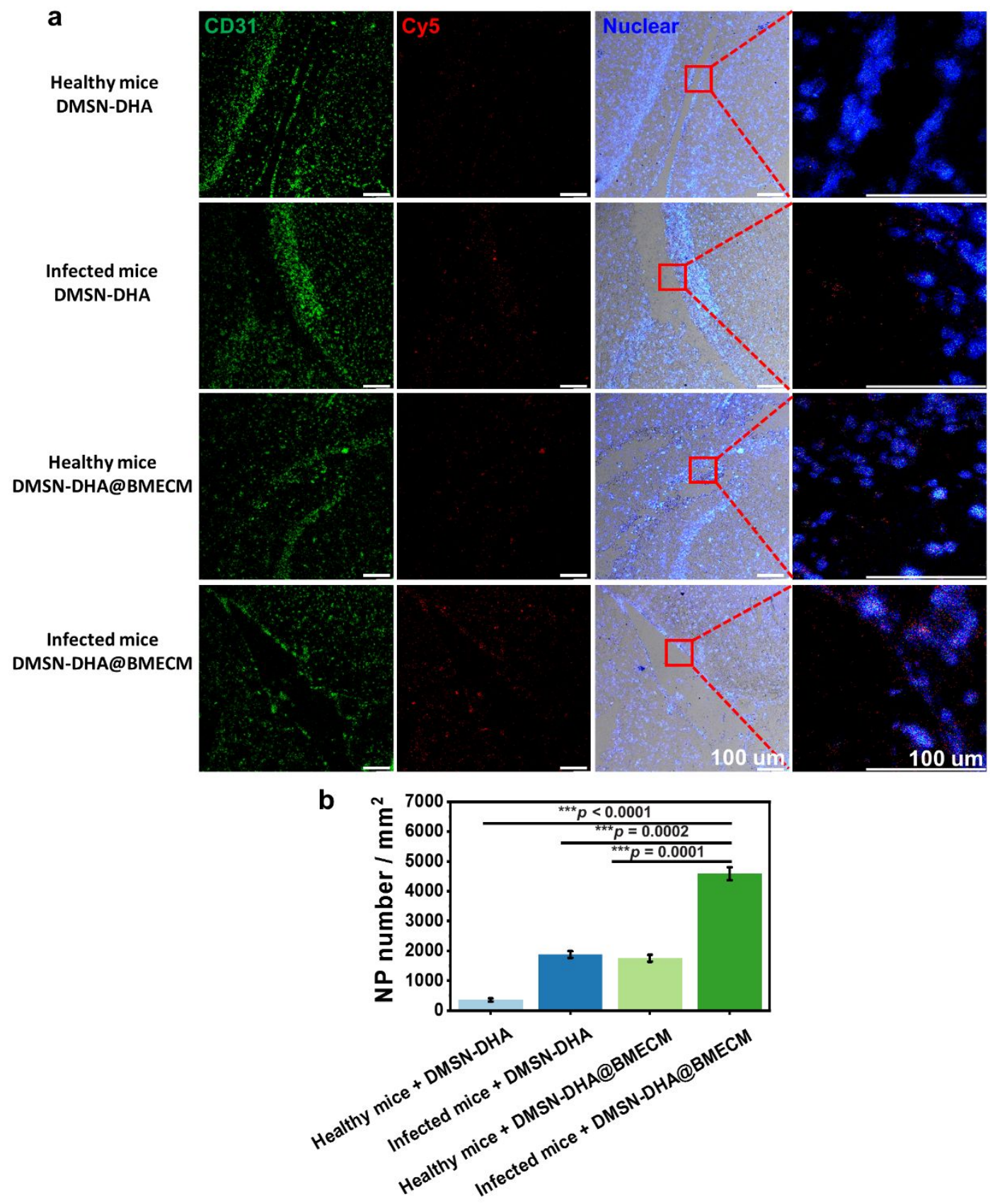

Figure S20. Fluorescence immunoassay experiment of mice brain tissues for different treatment groups. (a) Fluorescence immunoassay test of mice brain tissues. (b) Nanodrug accumulation analysis of different treatment groups. Each experiment was repeated three times. 

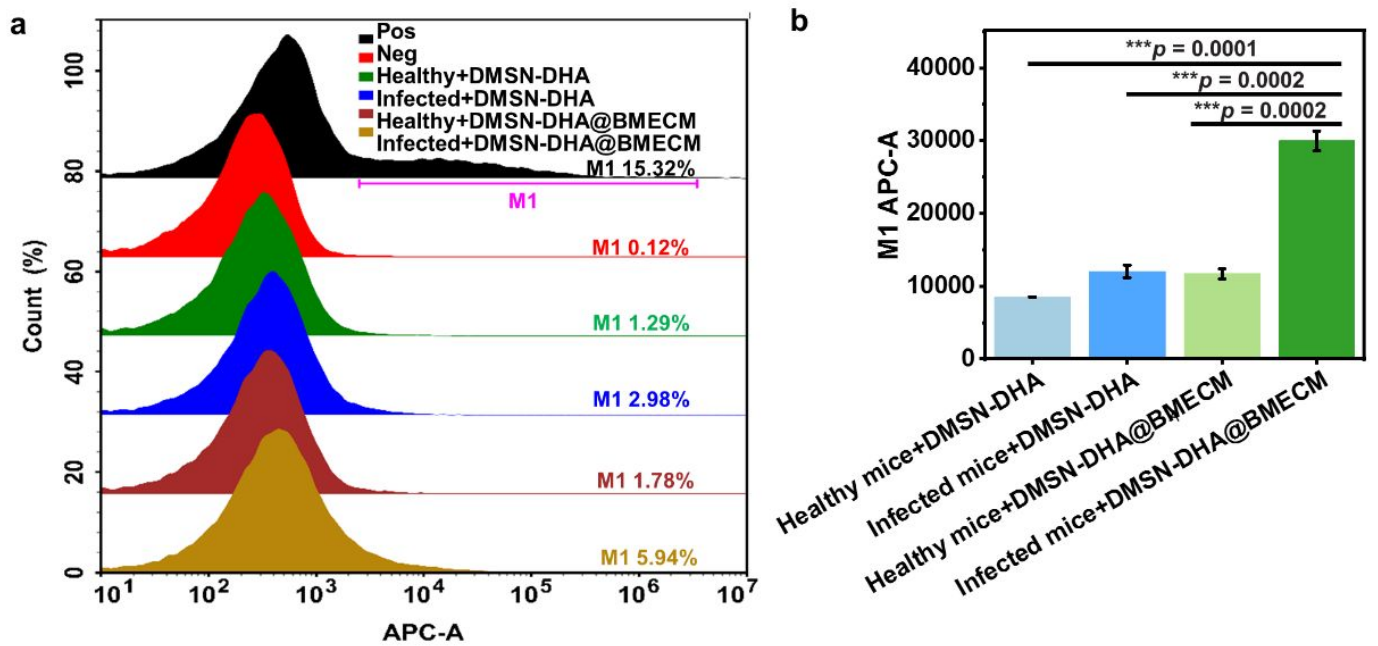

Figure S21. FCM test of mice brain for different treatment groups. (a) FCM assay of mice brains under different treatment. The "Neg" was a negative control group from untreated healthy mice. The "Pos" means positive control; it came from the "Neg" with adding $2 \mu \mathrm{g} / \mathrm{mL}$ DMSN-DHA@BMECM. For the FCM assay, the Cy5 dyes detected by the APC-A channel were labeled on the DMSN vectors for DMSN-DHA and DMSN-DHA@BMECM. (b) Nanodrug accumulation analysis of different treatment groups. Each experiment was repeated three times. 

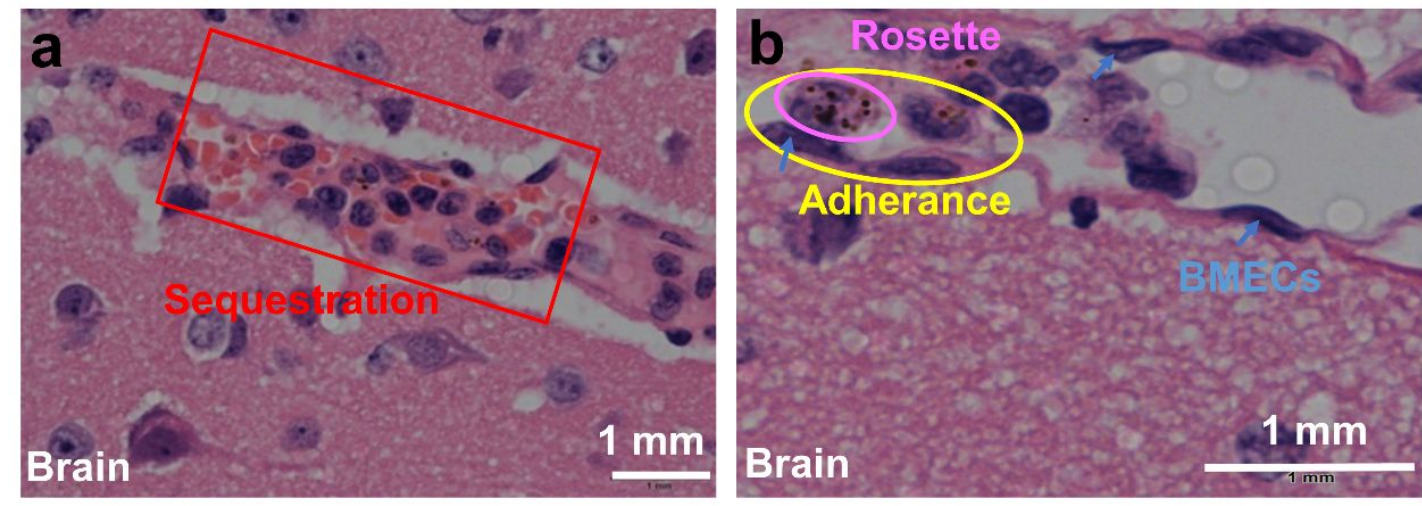

Figure S22. Histological observations in brain tissue from $P b A$-infected $C 57 B L / 6 N$ mice. (a) Sequestration of infected RBCs, RBCs, and inflammatory cells within the brain capillary from $P b A$-infected mice (the red rectangle region). Scale bar: $1 \mathrm{~mm}$. (b) The infected RBCs adhered to brain endothelial cells (BMECs) in the capillary. The pink oval showed a rosette, and the yellow oval indicated areas of adherence between infected RBCs and endothelial cells in the capillary. The blue arrows showed BMECs. Scale bar: $1 \mathrm{~mm}$. The infected RBCs directly participated in cytoadherence to BMECM, and rosettes formed by infected RBCs, normal RBCs, and inflammatory cells were also detected in the capillary, leading to obstructed brain capillaries and severe pathology of ECM in mice from the untreated group. These effects led to obstruction of brain capillaries and the severe pathology characteristic of experimental cerebral malaria observed in the untreated group. 


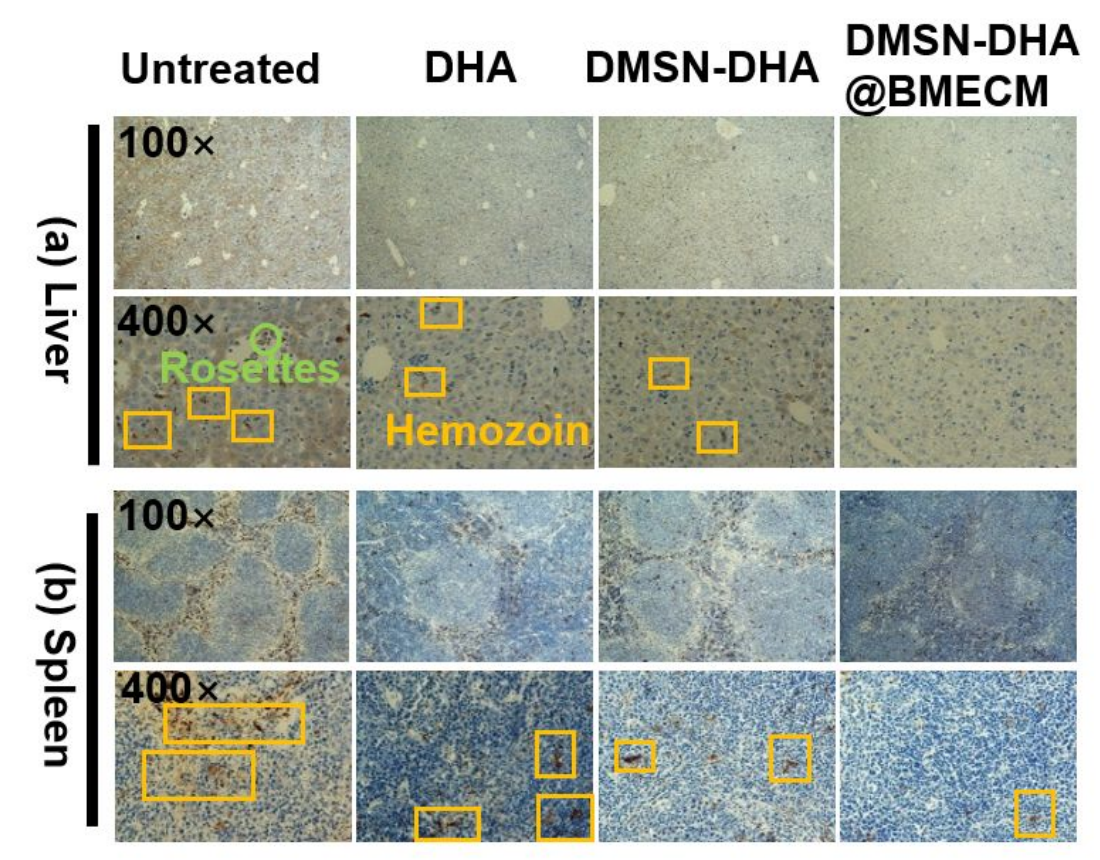

Figure S23. Prussian blue-stained histological observation of liver and spleen from $P b A$-infected $C 57 B L / 6 \mathrm{~N}$ mice following various drug treatments. Scale bars: $1 \mathrm{~mm}$.

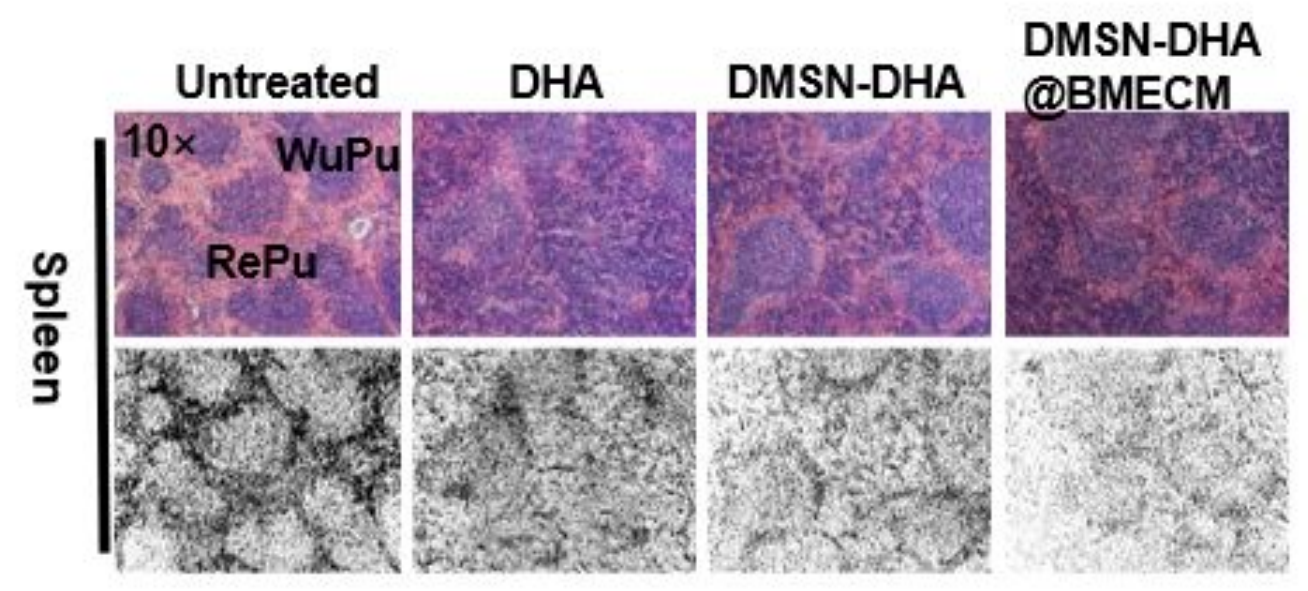

Figure S24. Representative H\&E stained images of the spleen after different treatments $(10 \times)$ (top). 8-bit grey pictures generated from image $\mathrm{J}$ software to show the $\mathrm{RePu}$ regions and WhRu regions (bottom). 


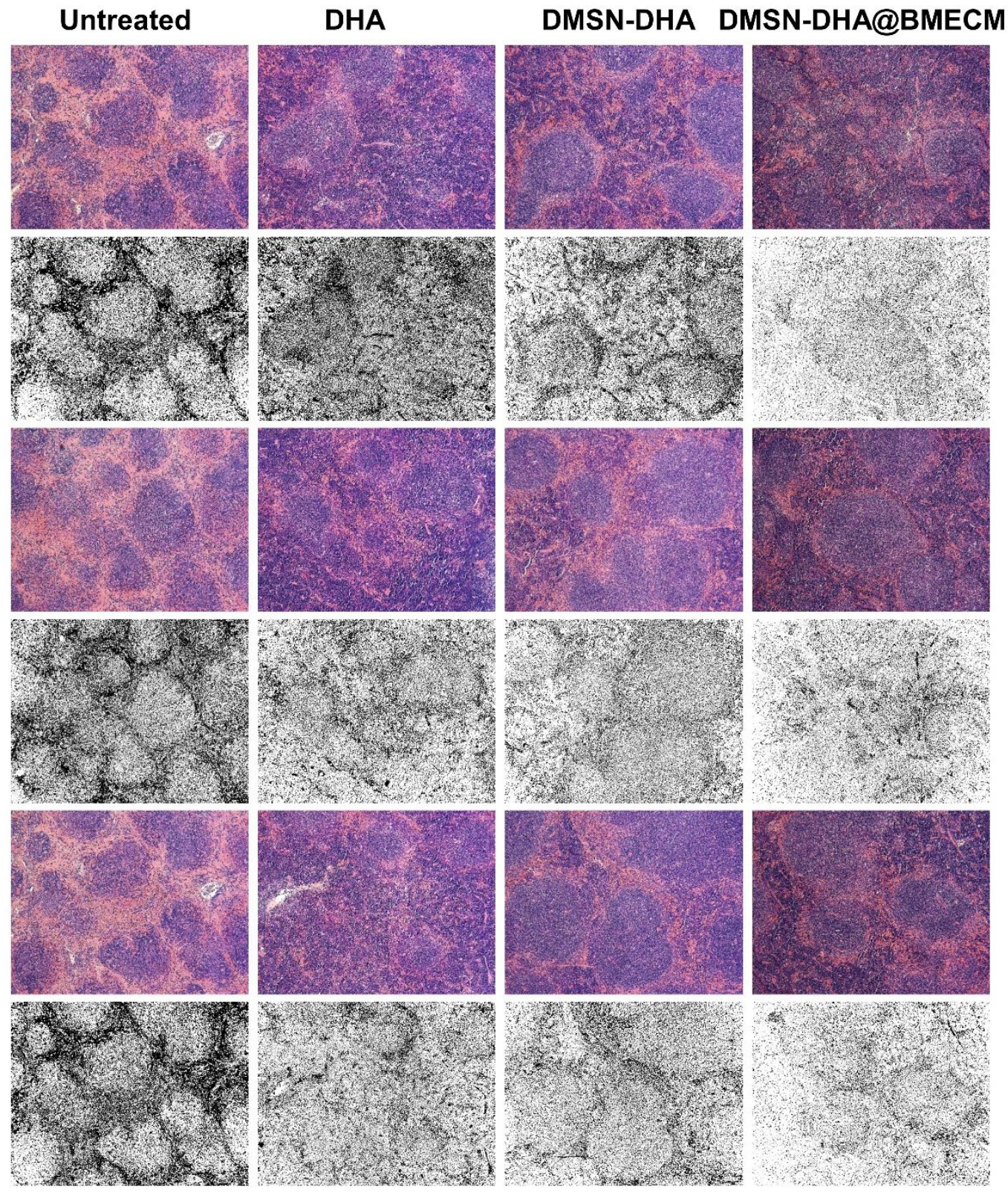

Figure S25. Original pictures and data for the $\mathrm{RePu}$ areas for the four treatment groups. The grey pictures were acquired from Image J software (version 1.50i, USA), representing the $\mathrm{RePu}$ area. 

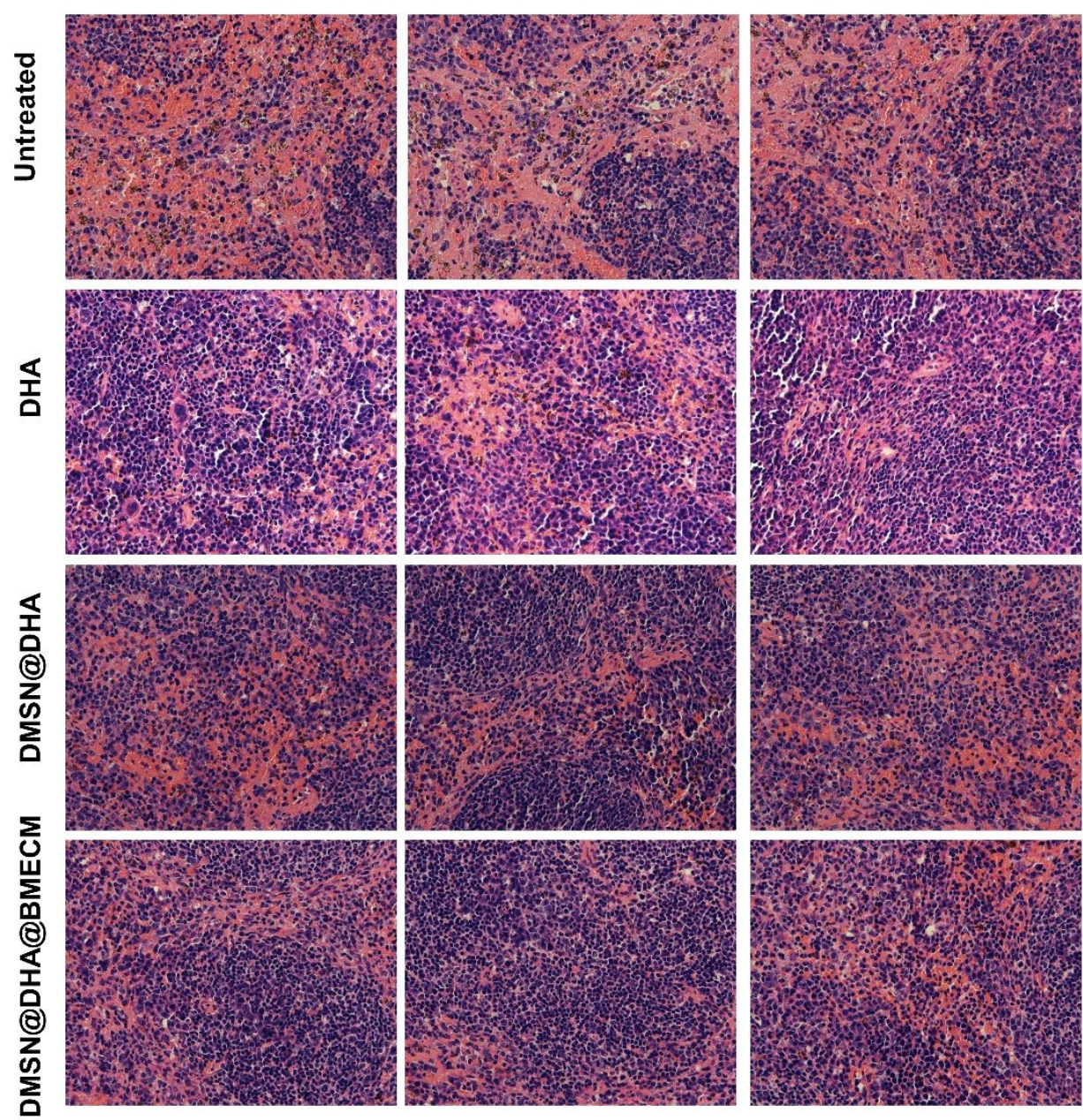

Figure S26. Representative pictures for the number of RBCs in images of HE-stained spleen from $P b A$-infected $C 57 B L / 6 N$ mice after different treatments. Each experiment was performed in triplicate. 


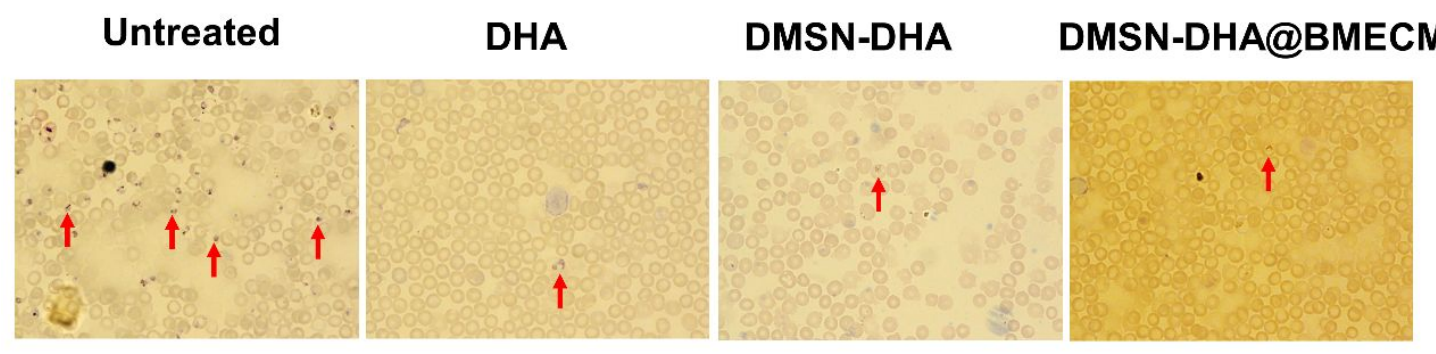

Figure S27. Parasitaemia detection in blood from $\mathrm{PbA}$-infected $\mathrm{C} 57 \mathrm{BL} / 6 \mathrm{~N}$ mice after drug treatment. Giemsa-stained blood smears of mice infected with $P b A$ on D8 post-infection (magnification is $1,000 \times$ ). The red arrows indicated infected RBCs. 
a

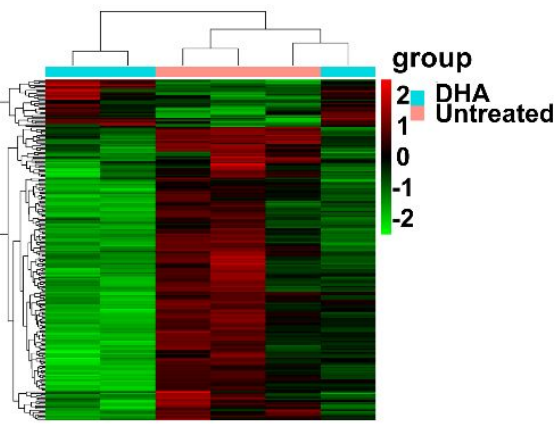

C

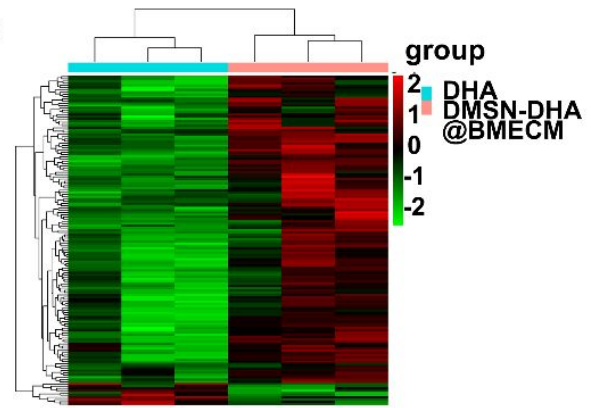

b

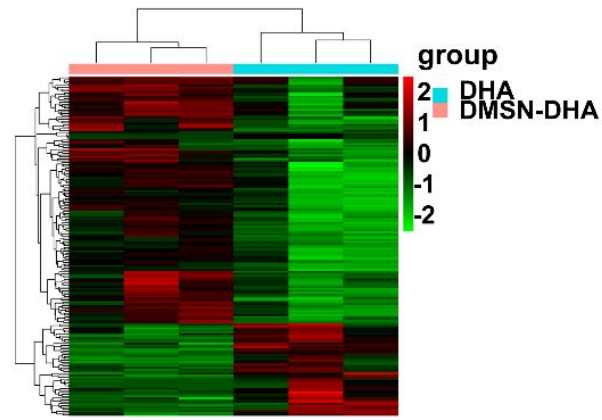

d

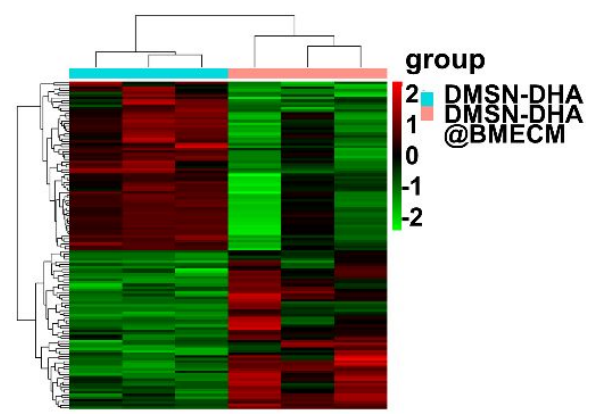

Figure S28. Heatmap analysis of differentiated expressed genes (DEGs). (a) Heatmap analysis of untreated and DHA-treated groups. (b) Heatmap analysis of DHA- and DMSN-DHA-treated groups. (c) Heatmap analysis of DHA- and DMSN-DHA@BMECM-treated groups. (d) Heatmap analysis of DMSN-DHA- and DMSN-DHA@BMECM-treated groups. 

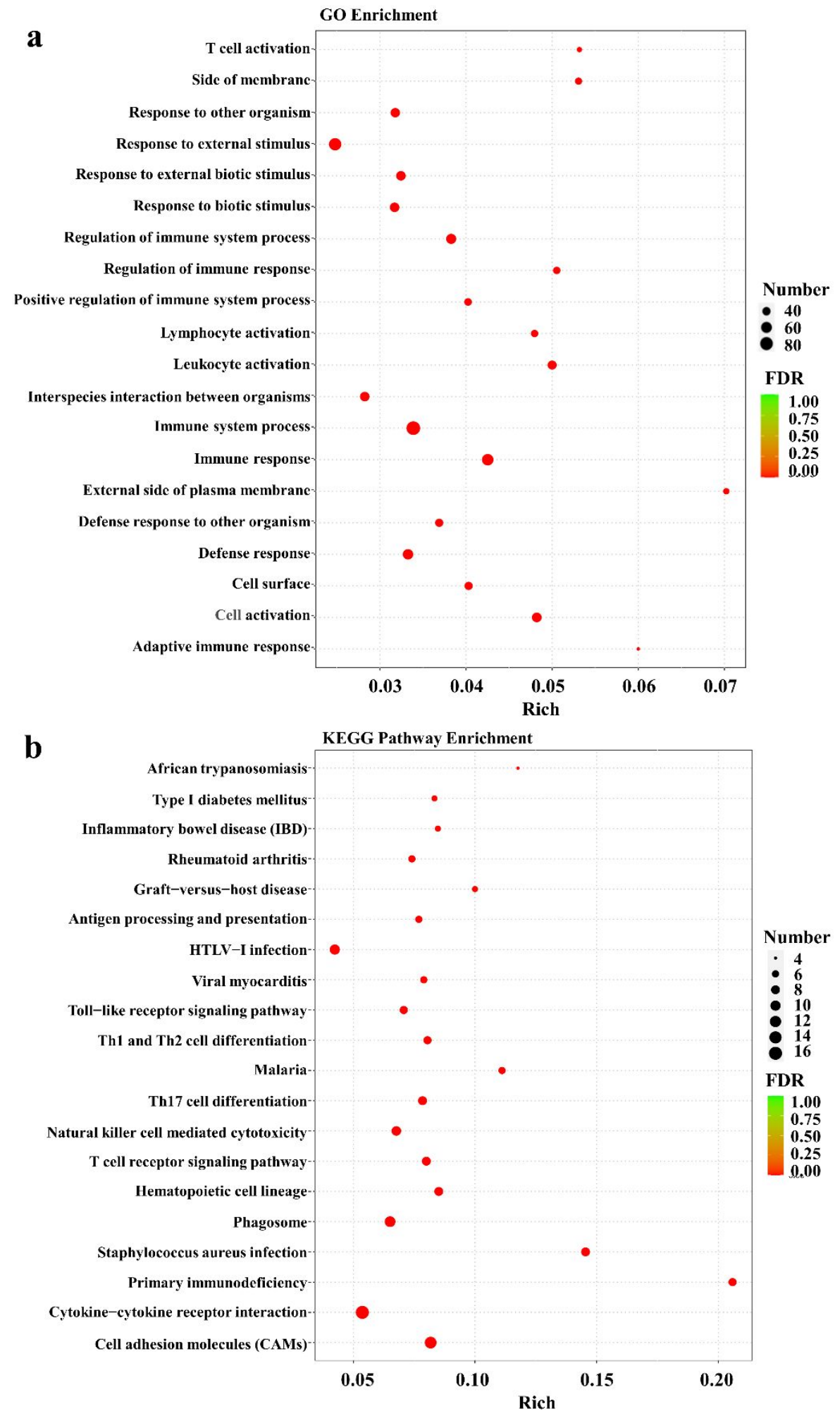

Figure S29. mRNA enrichment images of data obtained from DHA- and DMSN-DHA-treated groups. (a) GO enrichment analysis. (b) KEGG enrichment analysis. 
a

GO Enrichment

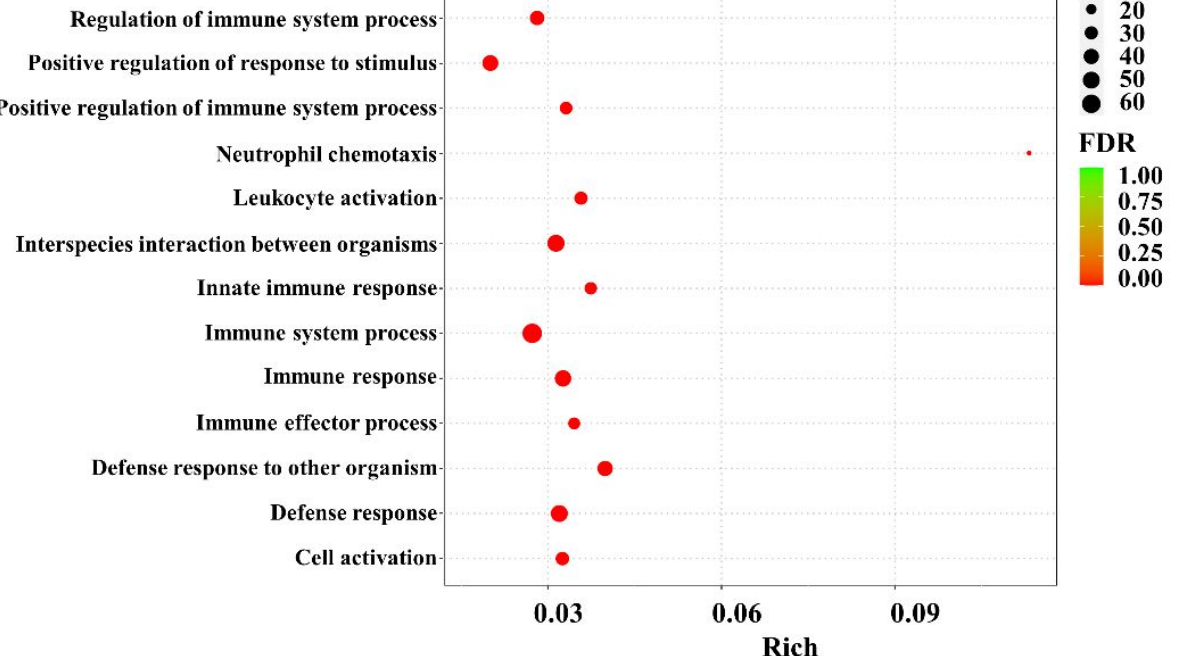

b

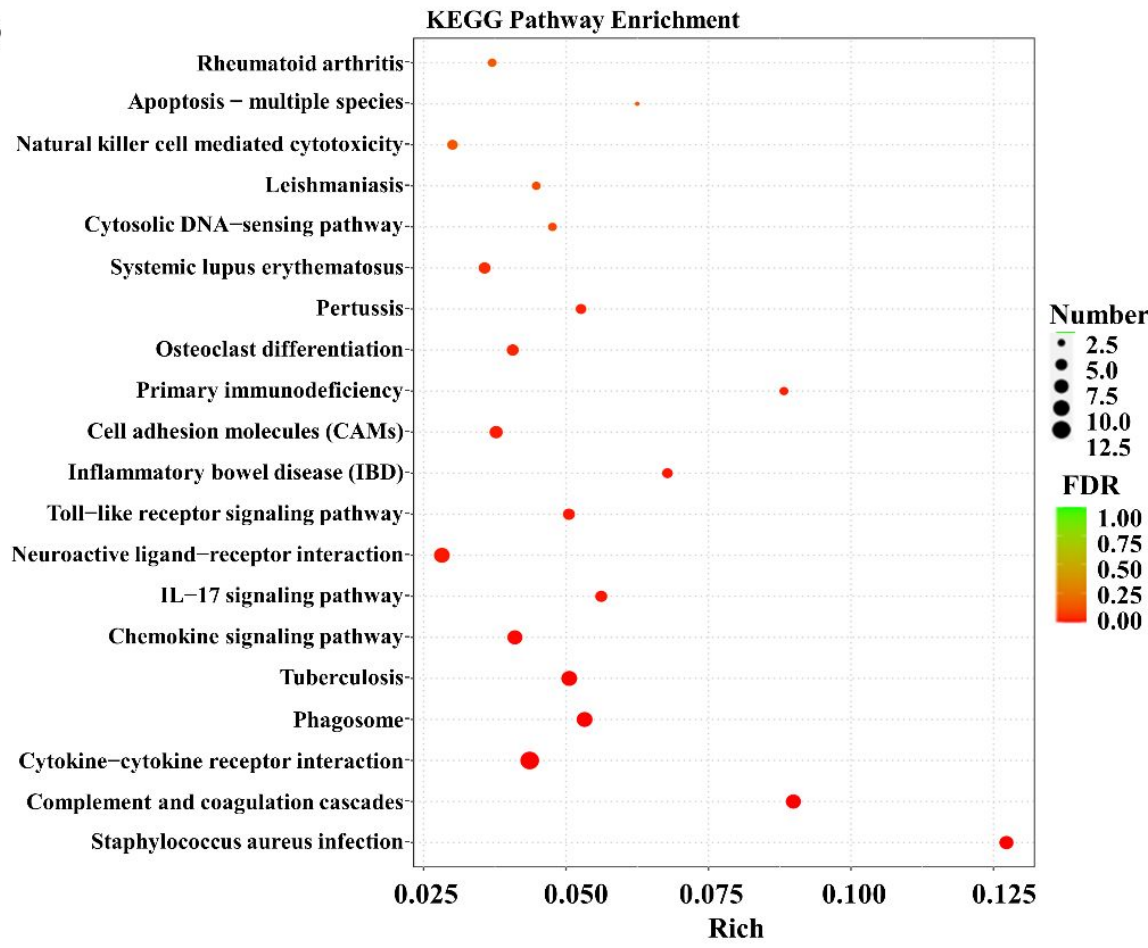

Figure S30. mRNA enrichment images of data obtained from DHA- and DMSN-DHA@BMECM-treated groups. (a) GO enrichment analysis. (b) KEGG enrichment analysis. 
a

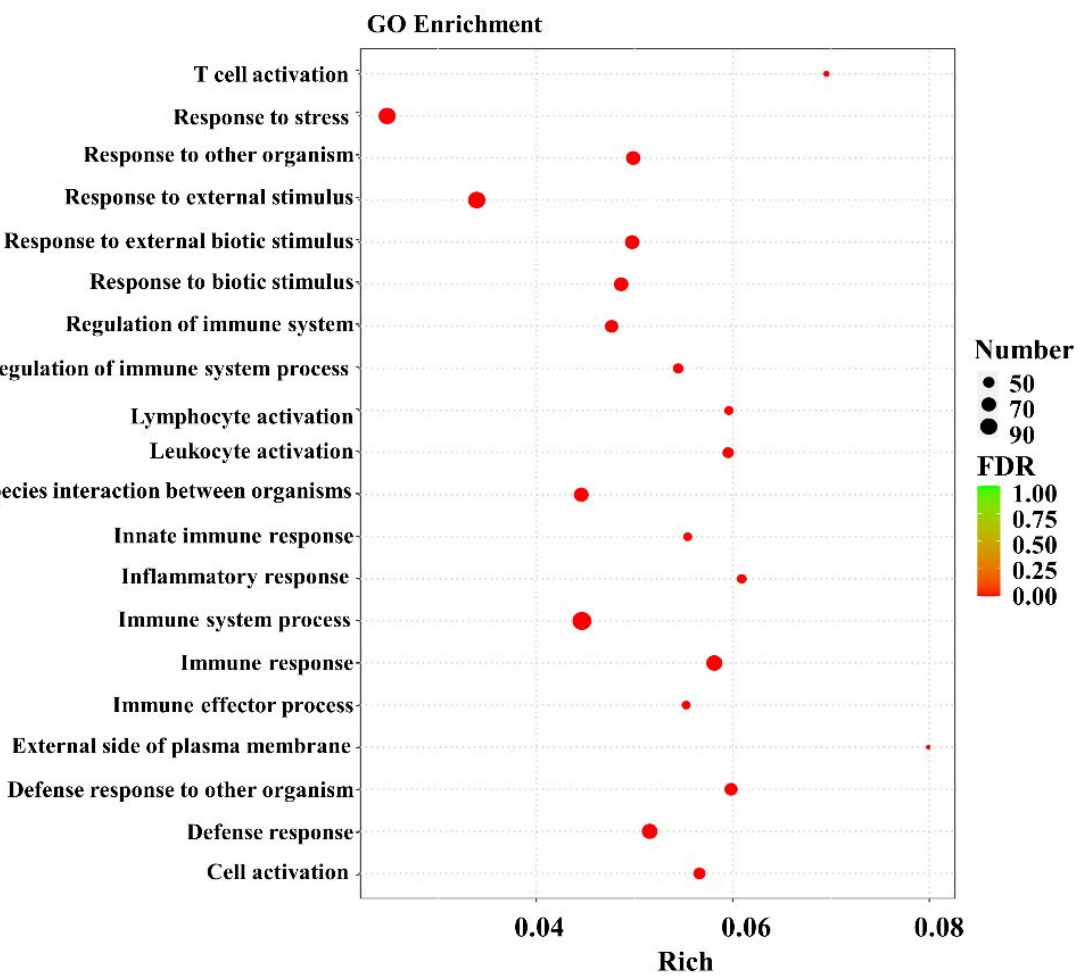

b

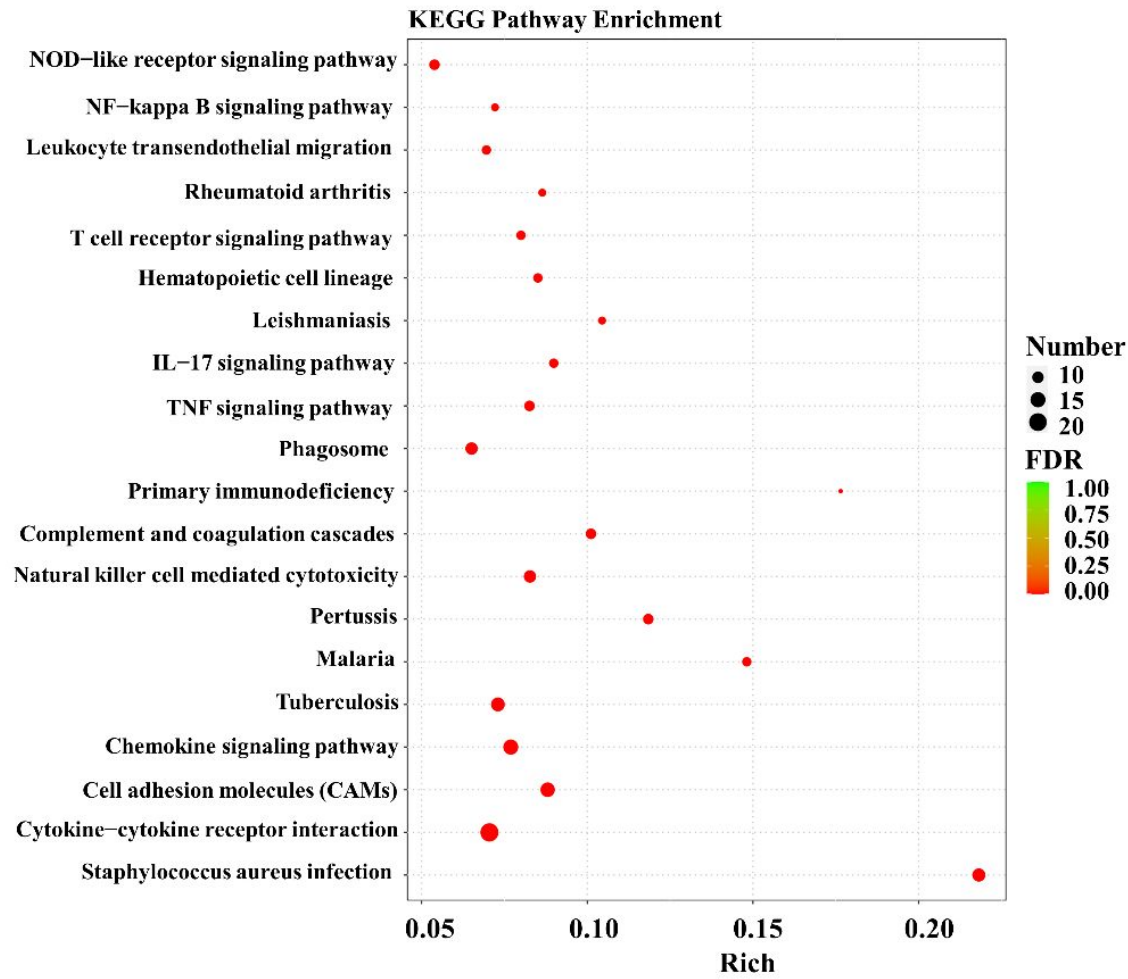

Figure S31. mRNA enrichment images of data obtained from untreated and DHA-treated groups. (a) GO enrichment analysis. (b) KEGG enrichment analysis. 


\section{SUPPLEMENTARY TABLES}

Table S1. The FCM data of hBMECs incubated with different human cell membrane clocked DMSN nano vectors.

\begin{tabular}{|c|c|c|c|c|}
\hline \multirow[t]{2}{*}{ Group } & \multicolumn{4}{|c|}{ APC-A (a.u.) } \\
\hline & FL1 & FL2 & FL3 & Mean \\
\hline DMSN@hBMECM & 385469 & 401766 & 396453 & $394562 \pm 8311$ \\
\hline DMSN@NHDFM & 173620 & 175307 & 174417 & $174448 \pm 843$ \\
\hline DMSN@U87M & 302583 & 3020587 & 296024 & $300221 \pm 3644$ \\
\hline DMSN@HUVECM & 332431 & 321096 & 315696 & $323074 \pm 8541$ \\
\hline DMSN@hRBCM & 76902 & 85307 & 77841 & $80016 \pm 4605$ \\
\hline PBS & 1584 & 1639 & 1607 & $1610 \pm 27$ \\
\hline
\end{tabular}

Table S2. The RePu areas for the four treatment groups.

\begin{tabular}{lcccc}
\hline \multirow{2}{*}{ Group } & \multicolumn{4}{c}{ RePu (pixels) } \\
\cline { 2 - 5 } & $\mathbf{1}$ & $\mathbf{2}$ & $\mathbf{3}$ & Mean \\
\hline Untreated & $\mathbf{8 0 6 9 8 1}$ & $\mathbf{8 7 4 5 6 2}$ & $\mathbf{8 6 1 1 2 0}$ & $\mathbf{8 4 7 5 5 4} \pm \mathbf{3 5 7 7 4}$ \\
DHA & $\mathbf{5 4 8 8 2 5}$ & $\mathbf{5 5 5 1 9 6}$ & $\mathbf{5 4 4 6 6 7}$ & $\mathbf{5 4 9 5 6 2} \pm \mathbf{5 3 0 3}$ \\
DMSN-DHA & $\mathbf{5 0 9 3 7 7}$ & $\mathbf{5 0 8 0 0 7}$ & $\mathbf{5 1 4 5 9 6}$ & $\mathbf{5 1 0 6 6 0} \pm \mathbf{3 4 7 6}$ \\
DMSN-DHA@BMECM & $\mathbf{2 3 8 0 6 5}$ & $\mathbf{3 7 4 5 3 3}$ & $\mathbf{2 3 1 4 7 1}$ & $\mathbf{2 8 1 3 5 6} \pm \mathbf{8 0 7 6 0}$ \\
\hline
\end{tabular}




\section{SUPPLEMENTARY REFERENCES}

1. Nacer, A.; Movila, A.; Sohet, F.; Girgis, N. M.; Gundra, U. M.; Loke, P.; Daneman, R.; Frevert, U. Experimental Cerebral Malaria Pathogenesis-Hemodynamics at the Blood Brain Barrier. PLoS Pathog. 2014, 10 (12), e1004528.

2. Carroll, R. W.; Wainwright,M. S. Kim, K.-Y.; Kidambi, T.; Mez, N. D. G.; Taylor, T.; Haldar, K. A Rapid Murine Coma and Behavior Scale for Quantitative Assessment of Murine Cerebral Malaria. PLoS One 2010, 5 (10), e13124.

3. Zhang, K.; Meng, X.; Yang, Z.; Cao, Y.; Cheng, Y.; Wang, D.; Lu, H.; Shi, Z.; Dong, H.; Zhang, X. Cancer Cell Membrane Camouflaged Nanoprobe for Catalytic Ratiometric Photoacoustic Imaging of MicroRNA in Living Mice. Adv. Mater. 2019, 31 (12), e1807888.

4. Shao, D.; Li, M.; Wang, Z.; Zheng, X.; Lao, Y. H.; Chang, Z.; Zhang, F.; Lu, M.; Yue, J.; Hu, H.; Yan, H.; Chen, L.; Dong, W. F.; Leong, K. W. Bioinspired Diselenide-Bridged Mesoporous Silica Nanoparticles for Dual-Responsive Protein Delivery. Adv. Mater. 2018, 30, e1801198.

5. Liu, C.; Wang, D.; Zhang, S.; Cheng, Y.; Yang, F.; Xing, Y.; Xu, T.; Dong, H.; Zhang, X. Biodegradable Biomimic Copper/Manganese Silicate Nanospheres for Chemodynamic/Photodynamic Synergistic Therapy with Simultaneous Glutathione Depletion and Hypoxia Relief. ACS Nano 2019, 13 (4), 4267-4277.

6. Wang, D.; Dong, H.; Li, M.; Cao, Y.; Yang, F.; Zhang, K.; Dai, W.; Wang, C.; Zhang, X. Erythrocyte-Cancer Hybrid Membrane Camouflaged Hollow Copper Sulfide Nanoparticles for Prolonged Circulation Life and Homotypic-Targeting Photothermal/Chemotherapy of Melanoma. ACS Nano 2018, 12 (6), 5241-5252.

7. He, X.; Yan, J.; Zhu, X.; Wang, Q.; Pang, W.; Qi, Z.; Wang, M.; Luo, E.; Parker, D. M.; Cantorna, M. T.; Cui, L.; Cao, Y. Vitamin D Inhibits the Occurrence of Experimental Cerebral Malaria in Mice by Suppressing the Host Inflammatory Response. J. Immunol. 2014, 193 (3), 1314-1323.

8. Tang, S.; Zhang, F.; Gong, H.; Wei, F.; Zhuang, J.; E. K.; Berta, E.-F.; Ávila, C. H., Zhou, Z.; Li, Z.; Yin, L.; Dong, H.; R. H. F., Zhang, X.; Zhang, L.; Wang, J. Enzyme-powered Janus Platelet Cell Robots for Active and Targeted Drug Delivery. Sci. Robot. 2020, 5 (43), eaba6137.

9. Huang, S.; Zhang, Q.; Yao, H.; Wang, W.; Zhang, J.-R.; Zhu, J.-J. Quantitative Detection and Imaging of Multiple Biological Molecules in Living Cells for Cell Screening. ACS Sens. 2020, 5 (4), 1149-1157.

10. Zhang, N.; Wang, Y.; Wu, R.; Xu, C.; Nie, J. J.; Zhao, N.; Yu, B.; Liu, Z.; Xu, F. J. Oxidation-Responsive Nanoassemblies for Light-Enhanced Gene Therapy. Small 2019, 15 (45), e1904017.

11. Hu, R.-S.; He, J.-J.; Elsheikha, H. M.; Zou, Y.; Ehsan, M.; Ma, Q.-N.; Zhu, X.-Q.; Cong, W. Transcriptomic Profiling of Mouse Brain During Acute and Chronic Infections by Toxoplasma Gondii Oocysts. Front. Microbiol. 2020, 11, 570903.

12. Kim, D.; Paggi, J. M.; Park, C.; Bennett, C.; Salzberg, S. L. Graph-based Genome Alignment and Genotyping with HISAT2 and HISAT-genotype. Nat. 
Biotechnol. 2019, 37 (8), 907-915.

13. Love, M. I.; Huber, W.; Anders, S., Moderated Estimation of Fold Change and Dispersion for RNA-seq Data with DESeq2. Genome Biol. 2014, 15 (12), 550.

14. Young, M. D.; Wakefield, M. J.; Smyth, G. K.; Oshlack, A. Gene Ontology Analysis for RNA-seq: accounting for Selection Bias. Genome Biol. 2010, 11 (2), R14.

15. Kanehisa, M.; Goto, S. KEGG: Kyoto Encyclopedia of Genes and Genomes. Nucleic Acids Res. 2000, 28 (1), 27-30. 